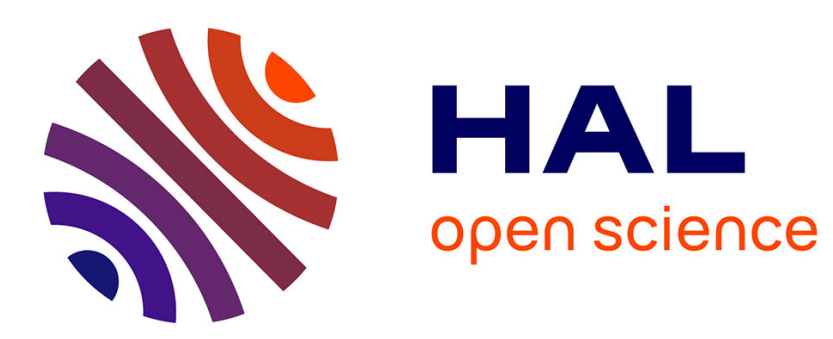

\title{
Analysis of continental midcrustal strain localization induced by microfracturing and reaction-softening
}

F. Gueydan, Y. Leroy, Laurent Jolivet, Philippe Agard

\section{To cite this version:}

F. Gueydan, Y. Leroy, Laurent Jolivet, Philippe Agard. Analysis of continental midcrustal strain localization induced by microfracturing and reaction-softening. Journal of Geophysical Research, 2003, 108, pp.1-17. 10.1029/2001JB000611 . hal-00022391

\section{HAL Id: hal-00022391 \\ https://hal.science/hal-00022391}

Submitted on 29 Jan 2021

HAL is a multi-disciplinary open access archive for the deposit and dissemination of scientific research documents, whether they are published or not. The documents may come from teaching and research institutions in France or abroad, or from public or private research centers.
L'archive ouverte pluridisciplinaire HAL, est destinée au dépôt et à la diffusion de documents scientifiques de niveau recherche, publiés ou non, émanant des établissements d'enseignement et de recherche français ou étrangers, des laboratoires publics ou privés. 


\section{Analysis of continental midcrustal strain localization induced by microfracturing and reaction-softening}

Frédéric Gueydan ${ }^{1,2}$ and Yves M. Leroy

Laboratoire de Mécanique des Solides, Ecole polytechnique, Palaiseau, France

Laurent Jolivet and Philippe Agard

Laboratoire de Tectonique, Université Pierre et Marie Curie, Paris, France

Received 9 May 2001; revised 28 June 2002; accepted 20 August 2002; published 1 February 2003.

[1] Low-angle extensional shear zones, which often characterize the brittle-ductile transition of the continental crust, are seen here to result from strain localization. The potentially destabilizing deformation mechanism is assumed to be the progressive transformation of fractured coarse feldspar grains into white mica as observed in the East Tenda Shear Zone, Alpine Corsica. The coupling between microfracturing and feldspar-tomica reaction is coeval with strain localization that occurred in that field case at a depth close to $15 \mathrm{~km}$. This reaction is proposed as the main destabilizing factor responsible for the onset of localization, with feldspar having a stationary dislocation creep flow stress larger than mica. To test this hypothesis, a rheological model is constructed based on the field observations for a mixture of three phases - mica, quartz and feldspar - deforming at a common strain rate. The phase concentrations change with time according to the feldspar-to-mica reaction, which takes place only if feldspar grains are fractured, a condition detected with the Mohr-Coulomb criterion. The tendency for the strain to localize is assessed by numerical means for the structure composed of an upper crust gliding rigidly over the lower crust, which sustains an overall simple shear. The onset of strain localization is defined by an increase of at least two orders of magnitude in strain rate over part of the lower crust. The upper crust gliding velocity has to be increased by at least a factor of 5 for localization to occur. The time lapse for this velocity change determines the depth of the shear zone $(15-17 \mathrm{~km})$. The kinetics of the metamorphic reaction and the final amount of white mica control its width $(1-4 \mathrm{~km})$. The time of the shear zone formation is less than half a million years. INDEX TERMS: 3210 Mathematical Geophysics: Modeling; 3230 Mathematical Geophysics: Numerical solutions; 8020 Structural Geology: Mechanics; 8030 Structural Geology: Microstructures; 8159 Tectonophysics: Evolution of the Earth: Rheology—crust and lithosphere; KEYWORDS: extention, continental crust, brittle-ductile transition, reaction softening strain localization

Citation: Gueydan, F., Y. M. Leroy, L. Jolivet, and P. Agard, Analysis of continental midcrustal strain localization induced by microfracturing and reaction-softening, J. Geophys. Res., 108(B2), 2064, doi:10.1029/2001JB000611, 2003.

\section{Introduction}

[2] Distributed midcrustal shear zones are characteristic of postorogenic-extension tectonites in metamorphic core complexes [Davis, 1983; Miller et al., 1983; Lister and Davis, 1989; Wernicke, 1992]. These shear zones lead to the formation of detachment planes, providing an exhumation mechanism at midcrustal depths. The question considered in

\footnotetext{
${ }^{1}$ Also at Laboratoire de Tectonique, Université Pierre et Marie Curie, Paris, France.

${ }^{2}$ Now at Geosciences Rennes, Université de Rennes 1, Rennes Cedex, France.

Copyright 2003 by the American Geophysical Union. 0148-0227/03/2001JB000611\$09.00
}

this paper is whether these shear zones could be initiated by a strain localization process in an homogeneous medium.

[3] The classical rheological models used for the lower crust are based on the extrapolation to geological conditions of experimentally determined power law creep (e.g., dislocation creep) for quartz or feldspar [Brace and Kohlstedt, 1980; Kirby and Kronenberg, 1987]. These models predict the strength decrease with depth but not the initiation of localization at midcrustal depths in the absence of a destabilizing mechanism [Poirier, 1980]. At these depths, various factors can have the softening role necessary to induce strain localization. Shear heating, grain size sensitive flow and reaction-softening are three candidates [Kirby, 1985]. Shear heating becomes relevant for temperature at least half the melting temperature [Poirier, 1980]. For a quartzofeldspathic continental crust, shear heating therefore dom- 
inates at depths close to the Moho [Fleitout and Froidevaux, 1980] and thus cannot be retained as a destabilizing factor for midcrustal conditions. Furthermore, grain-size sensitive rheology for the lower crust does not lead to localization at the brittle-ductile transition, but again, at depths close to the Moho, where the temperature is sufficiently large to activate diffusion creep deformation mechanism [Gueydan et al., 2001]. Reaction-softening is thus the only destabilizing factor of the three mentioned above which can be evoked, and is considered in this paper, to explain the trend for the strain to localize at the brittle-ductile transition.

[4] Midcrustal shear zones often consist of fine-grained mylonites within granitoïd host rocks typical of continental crust (see Fitz Gerald and Stünitz [1993] for a review on deformed granitoïds). At the brittle-ductile transition (greenschist facies grade), quartz predominantly deforms by dislocation creep and feldspar undergoes microcracking [Simpson, 1985], the latter being incorporated in the proposed rheological model. The pervasive transformation of feldspar into phyllosicate-rich assemblages is an evidence for reaction-softening in shear zones formed at the brittleductile transition [Mitra, 1978; White and Knipe, 1978; Dixon and Williams, 1983; Gapais, 1989; Wibberley, 1999]. The feldspar-to-mica reaction is the destabilizing factor which is considered here.

[5] Testing the assumption that strain can localize at midcrustal depths in a homogeneous medium as well as validating a new rheological model, which accounts for fracturing and reaction-softening, require quantitative data and have to be based on a real field case. For that purpose, evidence for both feldspar fracturing and reaction-softening are reported in this paper from a kilometric scale exhumed shear zone, the East Tenda Shear Zone (ETSZ). The Tenda massif, Alpine Corsica, is a good candidate to test the hypothesis that localization occurs without lithological contrast or any inherited structures in view of its homogeneous mineralogical composition (Hercynian granitoïd). Moreover, although the ETSZ is currently a contact between a continental unit (Tenda massif) and an oceanic unit (Schiste Lustrés nappe), the formation of the ETSZ is shown here to result from the coalescence of metric to kilometric scale top-to-the east shear bands. These geological observations permit thus to disregard the influence of inherited structures, important in other regions such as the Basin and Range [Wells, 2001].

[6] New structural and Pressure-Temperature data (PT) indicate that the 2-km-thick ETSZ was formed and active at a depth of $15 \mathrm{~km}$. Feldspar fracturing and the progressive transformation of feldspar into white mica are shown to be coeval. The mica concentration is found to increase with the strain intensity and reaches a maximum value of $50 \%$. On this basis, a rheological model is proposed for a mixture of the three solid phases, mica, feldspar and quartz. The three phases sustain a common strain rate and deform by dislocation creep. The concentration of mica and feldspar phases change with time due to the feldspar to mica reaction which is activated if the Mohr-Coulomb criterion is satisfied. This coupling results in the destabilizing effect which must have prevailed in the field since mica and feldspar have different dislocation creep flow stresses. The finite element solution of a 1-D simple shear model is proposed to quantify the depth at which shear zones form, their widths and their timing. It relies on a change in the velocity of the rigid upper crust gliding on the lower crust. The velocity change with respect to the Moho is necessary to raise the equivalent shear stress to the level necessary to trigger brittle effects [Gueydan et al., 2001]. It is found that a minimum velocity increase by a factor of five is necessary to induce feldspar to mica transformation at a depth close to $15 \mathrm{~km}$. This mineralogical change induces an increase of the strain rate which has to be at least of two orders of magnitude to define the onset of strain localization. The shear zones form during less than half a million years. The depth $(15-17 \mathrm{~km})$ and the width $(1-4 \mathrm{~km})$ of the predicted shear zone depend on the time lapse during which the upper crust velocity is increased, on the kinetics of the reaction and the percentage of feldspar transformed into mica. These results are consistent with the field observations for the ETSZ and therefore validate the rheological model proposed and the possibility to localize at midcrustal depths in a homogeneous medium.

\section{Deformation Mechanisms Responsible for Localization}

[7] The rheological model proposed in this paper is constructed from the interpretation of the observations made within the East Tenda Shear Zone (ETSZ). These observations are briefly presented for sake of completeness and the reader is referred to Jolivet et al. [1990], Daniel et al. [1996], and Gueydan [2001] for further information.

\subsection{Alpine Corsica Metamorphic Core Complex}

[8] Alpine Corsica corresponds to the northeastern part of the island and represents a nappe stack formed during the underthrusting of the European continental margin (Hercynian granitoïd, Tenda massif, Figure 1) under Ligurian oceanic units (Schistes Lustrés nappe) [Caron et al., 1981; Mattauer et al., 1981]. The main thrust contact between the Schistes Lustrés nappe and the Tenda Massif was active during the late Cretaceous and Eocene. Lithospheric stretching started in the Early Oligocene in the Liguro-Provençal Basin and then in the Middle Miocene in the Tyrrhenian Sea, leading to postorogenic extension in Alpine Corsica (Figure 1) [Jolivet et al., 1990]. The thrust contact between the Schistes Lustrés nappe and the Tenda massif was thus reworked as an extensional top-to-the-east shear zone, the ETSZ, associated with greenschist facies paragenesis [Waters, 1989; Jolivet et al., 1990]. The antiformal structure delineated by the extensional schistosity is a consequence of top-to-the-east shear with the schistosity rotating toward the main shearing direction with increasing strain (Figure 1).

[9] The intensity of the ductile deformation increases eastward, from a mostly undeformed core (site 1 of crosssection in Figure 1) to the mylonitic zone (site 2). The core of the massif is little affected by top-to-the-east metric scale shear bands (cross-section of Figure 2). Toward the east, the density of top-to-the-east shear bands drastically increases and their coalescence leads to the formation of the mylonitic foliation. The ETSZ is therefore not an inherited structure but a consequence of strain localization during the extension of the Corsica continental crust. The thickness of the ETSZ, estimated by the width of the region bounded by the first 


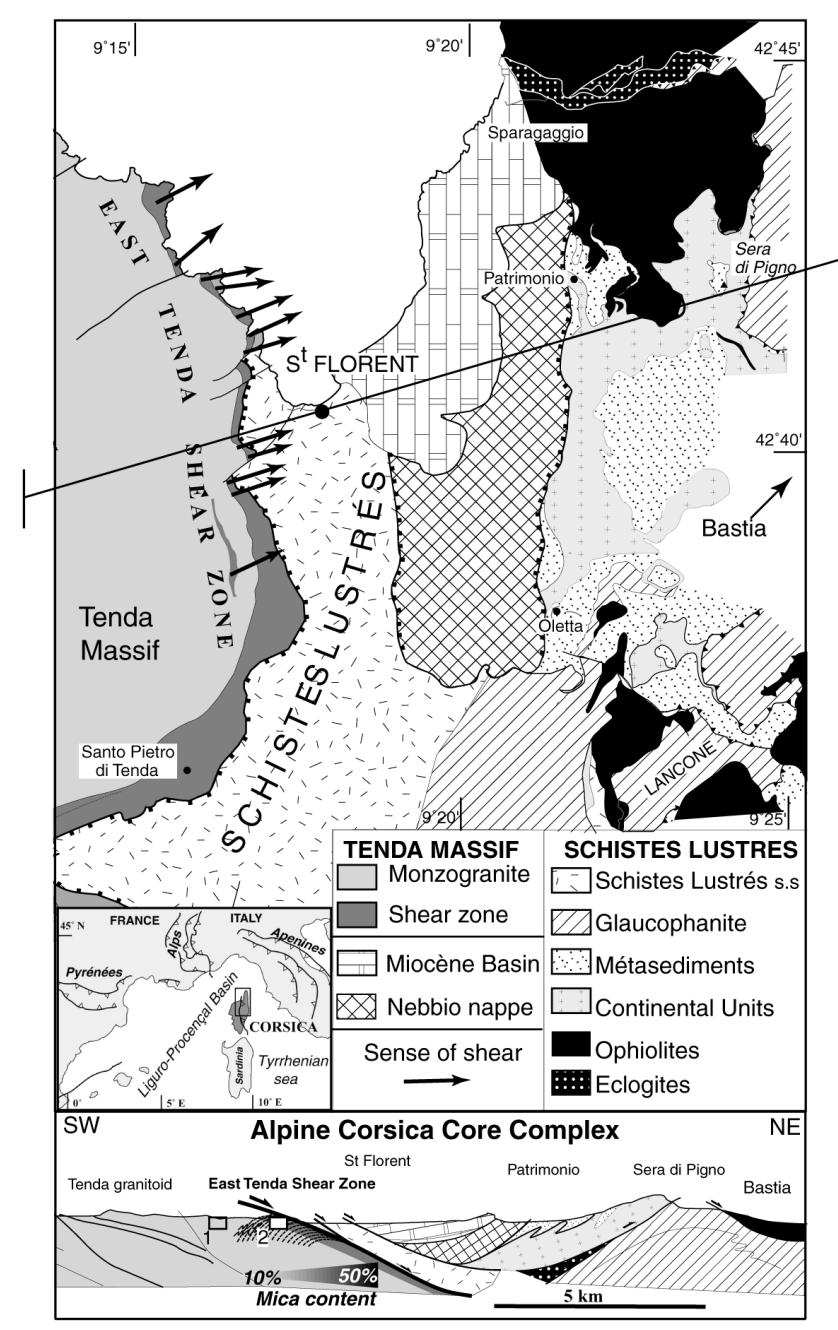

Figure 1. Location of Corsica, a geological map and an $\mathrm{E}-\mathrm{W}$ cross-section of the Alpine Corsica metamorphic core complex through Saint Florent. The stretching lineations of Daniel et al. [1996] and Gueydan [2001] are plotted within the ETSZ. Observations are reported at sites 1 and 2 marked by two squares on the cross-section.

top-to-the-east shear band and the mylonite (Figure 2), is therefore of the order of two kilometers. In summary, Alpine Corsica can be considered as a metamorphic core complex of Oligo-Miocene age similar to the Basin and Range and Aegean Sea [Jolivet et al., 1990; Fournier et al., 1991; Daniel et al., 1996].

\subsection{Microstructural Evolution Within the ETSZ}

[10] Microscopic observations are presented from two sites marked by the two squares in the cross-section of Figure 1.

[11] Figure 3a shows the characteristic microstructures documented in the center of the massif, where the granitoïd protolith is weakly deformed (site 1, Figure 2). Synthetic microfracturing within feldspar grains leads to grain-size reduction by an order of magnitude. Feldspar grain-size is also reduced by progressive recrystallization along the domino boundaries and internal deformation bands. These microstructures are compatible with an eastward sense of shear and are thus contemporaneous with the extensional deformation stage. Fine-grained white mica surround coarse feldspar grains within $\mathrm{C}$ planes. Within microfractures and thick deformation bands in feldspar, white mica are abundant and aligned with the shear planes. Feldspar fracturing is thus coeval with an increase in white-mica content. At this scale, quartz grains (size of $\sim 5 \mathrm{~mm}$, Figure $3 \mathrm{a}$ ) show thin intracrystalline deformation bands (thickness of 100 to $200 \mu \mathrm{m})$, consistent with top-to-the-east $\mathrm{C}^{\prime}$ planes.

[12] In the more intensely sheared region, at site 2 , the mean grain size for feldspar and quartz is approximately 100 $\mu \mathrm{m}$ (Figure 3b). However, some original coarse feldspar grains are preserved with a size of $500 \mu \mathrm{m}$, and coated by a mantle of white mica. Within $\mathrm{C}$ planes, the amount of white mica is larger than in site 1. Intracrystalline fracturing of feldspar is no longer observed. The new mylonitic foliation is defined by relatively narrow domains of fine-grained white mica separating domains of fine-grained quartz. Quartz displays textures indicative of dynamic recrystallization, with a grain-shape fabric oblique to the mylonitic foliation.

[13] In summary, it is suggested that from west to east, the increase in the shearing intensity induces an increase in the amount of feldspar transformed into mica. This increase is initiated by feldspar fracturing at a large distance from the mylonite (site 1). To quantify the increase in mica content, the volumetric proportion of the three principal solid phases (feldspar, quartz and mica) has been estimated by optical microscope. The mica proportion as a function of the distance to the mylonite is reported in Figure 2. In the undeformed granitoïd (site 1), where feldspar fracturing is observed, the mica proportion ranges between 5 and $20 \%$, with an average value of $10 \%$. Toward the east, mica concentration increases to reach a value of up to $40 \%$ in

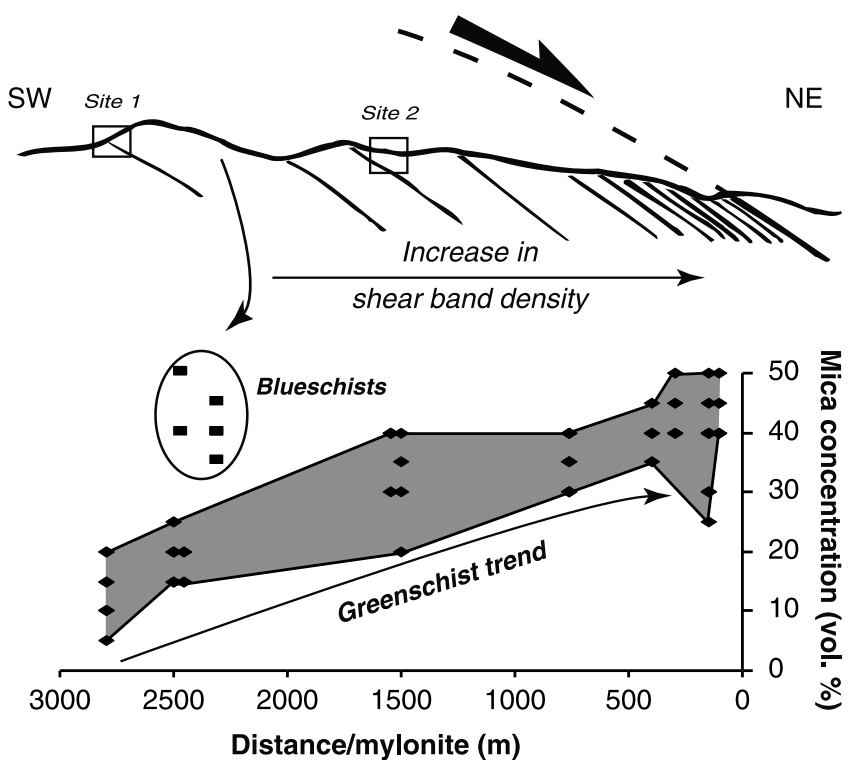

Figure 2. SW-NE schematic cross section of the ETSZ. The shear band density increases eastward. The volumetric concentration of mica has been optically determined throughout the ETSZ. Mica concentration as a function of the distance to the mylonite is also reported. The eastward increase in mica content is coeval with the increase in extensional shear band density (greenschist trend). Preserve blueschists paragenesis are characterized by a large value of mica content. 


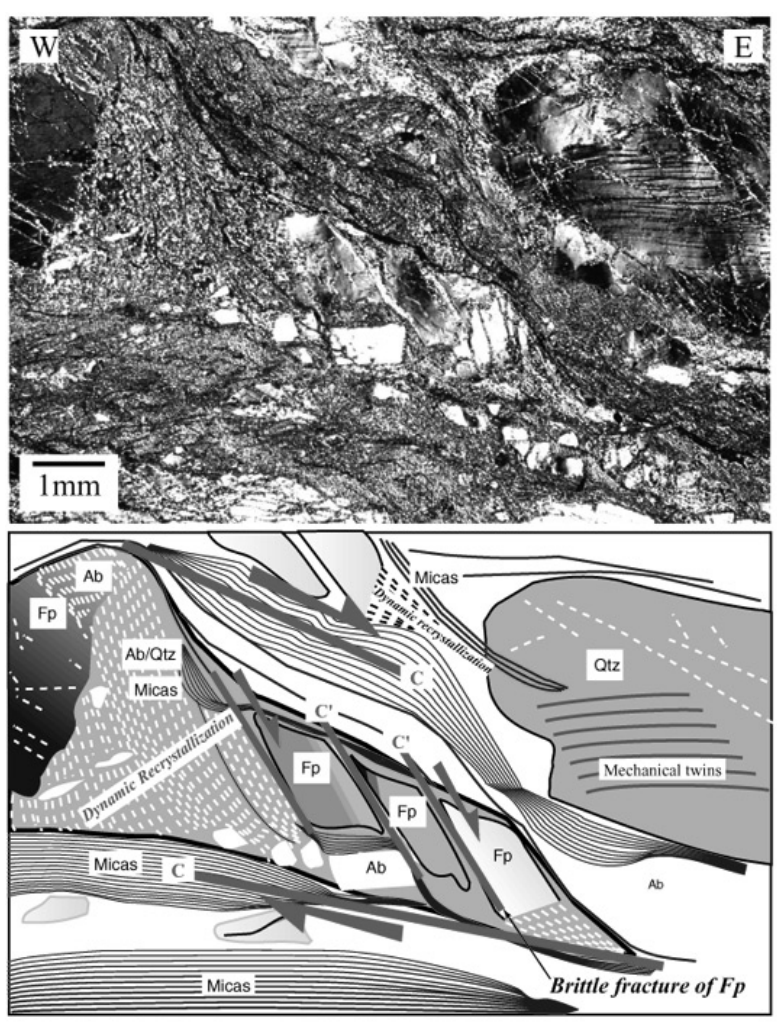

a

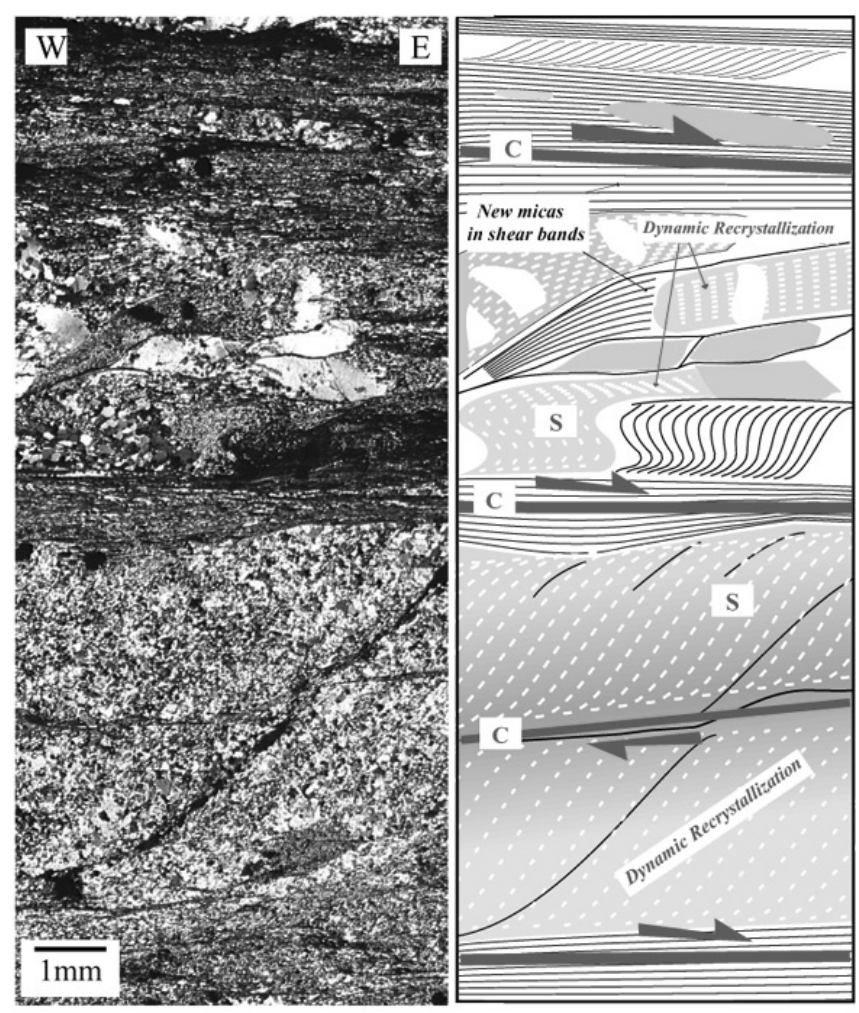

b

Figure 3. Thin sections, oriented $\mathrm{W}-\mathrm{E}$, and their interpretation. In a) from site 1 (Figure 2), a coarse feldspar grain is fractured and rimmed by a mantle of white mica. Quartz grain presents thin intracrystalline dynamic recrystallization bands. In b) from site 2, C-planes are essentially made of an aggregate of fine-grained white mica. The mean recrystallized grain size reaches a value of approximately $100 \mu \mathrm{m}$. See color version of this figure at back of this issue.

site 2 and up to $50 \%$ in the mylonite. It is found that within the ETSZ, the proportion of quartz remains stable at approximately $40 \%$. Therefore, from west to east, the proportion of the three solid phases changes as follows. Site 1 is characterized by $50 \%$ of feldspar, $40 \%$ of quartz and $10 \%$ of white mica. Toward the east, in the mylonite, between $50 \%$ to $80 \%$ of feldspar present in site 1 are transformed into mica. Therefore, the quantity of white mica reaches a concentration between $35 \%$ to $50 \%$, and the feldspar proportion is between $25 \%$ and $10 \%$.

[14] Note that for two thin sections (at $2.5 \mathrm{~km}$ from the mylonite, Figure 2) a concentration of $40-50 \%$ has been observed. These thin sections are characterized by the absence of greenschist paragenesis. The related outcrops are located between two shear bands and thus corresponds to preserve blueschists paragenesis. The presence of preserve high grade rocks and the progressive increase in shear bands density indicate that strain localization occurred in a homogeneous medium without the possibility to reactivate inherited structures.

\subsection{Activated Deformation Mechanisms for Feldspar, Quartz, and Mica}

[15] It may be concluded from the observations presented above that in the weakly deformed protolith (site 1), coarse feldspar grains are fractured and deformed by dislocation creep. Syn-tectonic alteration and dynamic recrystallization led to a drastic grain-size reduction, forming new grains of albite and quartz (and also some fine-grained white mica) with a grain size of the order of $100 \mu \mathrm{m}$. The recrystallization-accommodated dislocation creep was previously determined from experimental work to be the dominant deformation mechanism of feldspar for lower crustal conditions, due to the difficulty for dislocation gliding and climbing [Tullis and Yund, 1985, 1987]. Since the feldspar grain size is reduced by fracturing, feldspar then deforms only by dislocation creep, leading to a progressive grainsize reduction (recrystallization, site 2 ).

[16] From west to east, quartz is mainly deformed by dislocation creep and no intracrystalline brittle deformation is observed. Intracrystalline recrystallization bands are common features in quartz grains, highlighting the different dislocation creep accommodation for quartz and feldspar. From their experimental results, Hirth and Tullis [1992] stressed that dislocation creep accommodation is dislocation climb for quartz (regime 2 dislocation creep), whereas it is recrystallization by grain boundary migration for feldspar (regime 1 dislocation creep).

[17] The mechanical properties of phyllosilicates are highly anisotropic. If shortened perpendicular to the basal plane [001], the strength is comparable to quartz and feldspar. In contrast, if shortened at $45^{\circ}$ to [001], the phyllosilicate strength is at least one order of magnitude less [Kronenberg et al., 1990; Mares and Kronenberg, 


\section{P-T-time path}

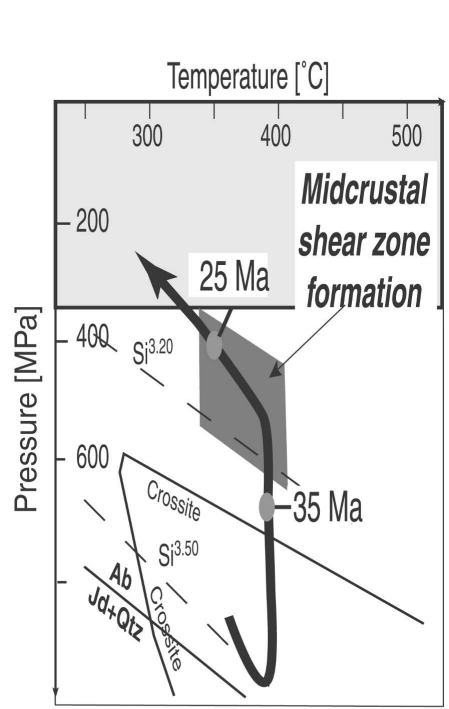

a)

\section{Alpine Corsica crust at early stage of extension}

1D model structure

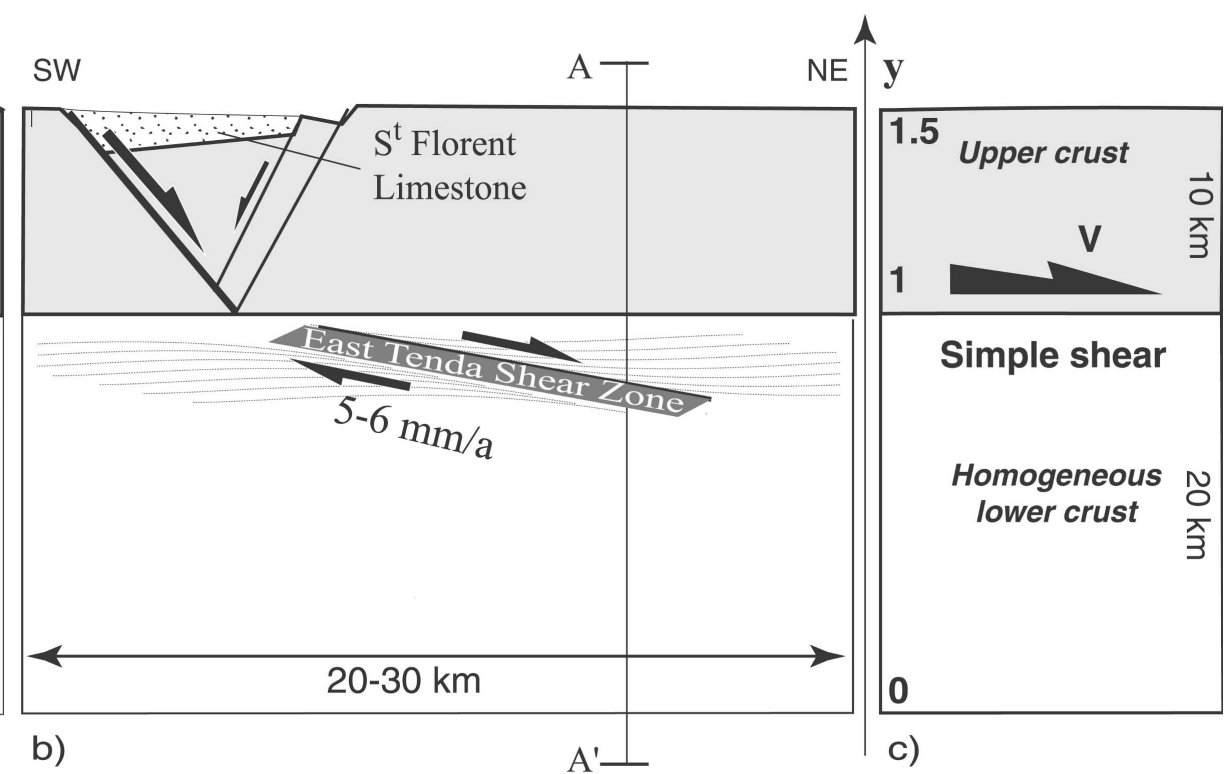

Figure 4. $\mathrm{P}-\mathrm{T}$-time path for the Tenda massif (a), the structure of Corsica crust at an early stage of extension (b) and the 1-D simple shear model structure used for the numerical simulation (c). The sodic blue amphibole (crossite) stability field is based on the work of Evans [1990]. The isoplete $\mathrm{Si}^{3.5}$ and $\mathrm{Si}^{3.2}$ for white mica (phengite) in the stability field of albite are based on Oberhänsli et al. [1995]. ${ }^{40} \mathrm{Ar} /{ }^{39} \mathrm{Ar}$ ages, measured from phengite, are from Brunet et al. [2000]. The 2-km wide ETSZ corresponds to an approximately $10^{\circ} \mathrm{NE}$ dipping extensional shear zone, active at depths of 15 to $17 \mathrm{~km}$. The upper crust was characterized by conjugate normal faults, permitting the St Florent limestone deposit. Far away from the upper crust normal faults, the Section $\mathrm{AA}^{\prime}$ in b) motivates the proposed 1-D simple shear model problem sketched in c). The dimensionless y-coordinate ranges from 0 at the Moho to 1.5 at the surface and takes for value 1 at the upper crust contact.

1993]. ETSZ mica are almost always oriented along the main schistosity and formed interconnected layers (mylonitic foliation, Figure 3b), suggested to be an interconnected weak layer [Handy, 1990]. Furthermore, oriented and interconnected phyllosilicates may deform by dislocation glide in nature [Knipe and Wintsch, 1985], suggesting that the same deformation mechanism as in the two other phases was activated.

\subsection{Depth, Temperature, and Timing of Shear Zone Formation}

[18] The validation of the localization analysis presented in section 6 requires an independent determination of the depth, the thickness and the timing of the ETSZ formation. These parameters are constrained from microprobing analysis.

[19] The $\mathrm{P}-\mathrm{T}$ path is given in Figure 4a. The maximum $\mathrm{P}-\mathrm{T}$ for Tenda blueschists are approximately $900 \mathrm{MPa}$ and $400^{\circ} \mathrm{C}$. Temperature was approximately constant $(T \simeq$ $400^{\circ} \mathrm{C}$ ) along the retrograde path, as suggested by the absence of interlayer variation in white mica [Agard et al., 2001]. The PT domain where midcrustal shear zones form is marked by the gray zone in Figure 4a.

[20] The microstructures presented in the previous section are consistent with the temperature conditions deduced from mineral assemblages. The presence of synthetic intracrystalline microfractures in feldspar indicates temperature close to $400^{\circ} \mathrm{C}$ [Pryer, 1993]. Furthermore, microcracks in feldspar correspond to an intermediate behavior between cataclastic flow and dislocation creep regime [Tullis and Yund, 1987]. These authors stressed that this intermediate deformation mechanism for feldspar and the ductility of quartz are compatible with lower greenschist facies conditions. Using $\mathrm{P}-\mathrm{T}$ values determined previously and considering a rather constant material density for the overburden rocks $(2800 \mathrm{~kg}$ $\mathrm{m}^{-3}$ ), the depth at which localized structures formed is of the order of $15-17 \mathrm{~km}$ (Figure 4). This depth and temperature $\left(400^{\circ} \mathrm{C}\right)$ are relevant to the brittle-ductile transition of the continental crust sustaining extension.

[21] The formation and the activity of the ETSZ is bounded between $35 \mathrm{Ma}$ and $25 \mathrm{Ma}$ (Figure 4a) [Brunet et al., 2000]. The exhumation rate for Tenda massif was such that it crossed the $350^{\circ} \mathrm{C}$ isotherm $25 \mathrm{Ma}$ ago at a depth of $15 \mathrm{~km}$ and crossed the $60^{\circ} \mathrm{C}$ isotherm $18 \mathrm{Ma}$ ago (fission track data [Jakni et al., 2000]) at a depth of $2 \mathrm{~km}$. The vertical exhumation rate is thus estimated to be approximately $2 \mathrm{~mm} / \mathrm{a}$, corresponding to $5-6 \mathrm{~mm} / \mathrm{a}$ along a $20^{\circ}$ north-east dipping extensional shear zone. The formation and the activity (e.g., exhumation of HP-LT metamorphic rocks) of the ETSZ has thus last less than $10 \mathrm{Ma}$.

[22] The geometry proposed in Figure $4 \mathrm{~b}$ and based on the work of Jolivet et al. [1990, 1998] is similar to the present situation of the Gulf of Corinth where active normal faults root in a shallow-dipping decollement at $8-10 \mathrm{~km}$ [Rigo et al., 1996]. Moreover, the first deposition of St Florent limestone in the Early Miocene (21 Ma [Ferrandini 
et al., 1996]) is associated with brittle normal faults inside the basin and along the western rim of the basin. The exact relations between the normal faults and the extensional shear zone at midcrustal depths are beyond the scope of this paper. It suffices in the present study to assume that normal faulting is associated with an increase in horizontal velocity of the upper crust and we shall concentrate on a vertical section $\mathrm{AA}^{\prime}$ (Figure $4 \mathrm{~b}$ ) far away form the upper crust normal faults. The proposed model structure thus corresponds to a 1-D simple shearing of the lower crust due to the rigid gliding of the upper crust, as sketched in Figure 4c.

\section{Reaction-Softening as a Destabilizing Factor}

[23] The microstructural observations coupled with the $\mathrm{P}-\mathrm{T}$-time estimations constrain in space and time the strain localization process, which could be defined in three steps as follows. First, the formation of centimetric scale shear bands in undeformed host rocks is coeval with the fracturing of coarse feldspar grains. Second, within these fractures, a progressive transformation of feldspar into white mica is initiated. Between $50 \%$ and $80 \%$ of feldspar are transformed into mica, leading to the formation of a fine-grained micarich mylonite. Third, the increase in the density of mica-rich shear bands is contemporaneous with the formation of a large scale extensional shear zone, namely the ETSZ. As deduced from the geological observations a representative elementary volume (REV) is composed of three solid phases, feldspar, quartz and mica. Within the REV, coarse feldspar grains are fractured and deformed by dislocation creep. Microfaults, nucleated in feldspar coarse grains, act as weakness planes along which free fluids available in neighboring rocks percolate. The presence of fluids in these microfaults leads to the pervasive transformation of feldspar into white mica, according to a reaction of the type

$$
\text { feldspar }+\mathrm{H}_{2} \mathrm{O} \rightleftharpoons \text { white mica. }
$$

The complexity of reaction (1) is presented by Hemley and Jones [1964]. For the purpose of our modeling, it is preferred to keep a generic reaction to stress the difference in rheological properties of the protolith (mainly feldspar) and the mylonite (mainly white mica).

[24] Fluid influx is required for reaction (1) to occur. The quantity of water for the transformation of feldspar into white mica is estimated as follows. In a REV of $1 \mathrm{~m}^{3}$, quartz, feldspar and mica are present in a volumetric proportion of 40,50 and $10 \%$, respectively. The transformation of half the present feldspar (assumed to be Kfeldspar $\mathrm{KSi}_{3} \mathrm{AlO}_{8}$ for this computation) required one mol of $\mathrm{H}_{2} \mathrm{O}$ per mol of mineral and thus a total of 2400 mol. Since the molar volume of water is close to $18 \mathrm{~cm}^{3}$ $\mathrm{mol}^{-1}$ at these PT conditions [e.g., Brown and Lamb, 1989], the required volume of $\mathrm{H}_{2} \mathrm{O}$ represents 4 vol $\% \mathrm{H}_{2} \mathrm{O}$ of the REV (43.2l). Similarly, 7 vol $\% \mathrm{H}_{2} \mathrm{O}$ are needed to permit the transformation of $80 \%$ of the initially present Kfeldspar into mica. These estimates are consistent with the amounts of fluids available in the protolith (water content of a monzogranite around $2-3$ vol $\% \mathrm{H}_{2} \mathrm{O}$, i.e., $1 \%$ wt $\mathrm{H}_{2} \mathrm{O}$ [Carmichael et al., 1974]) and with fluid flow reported in the literature at these depths [Walther and Orville, 1982;

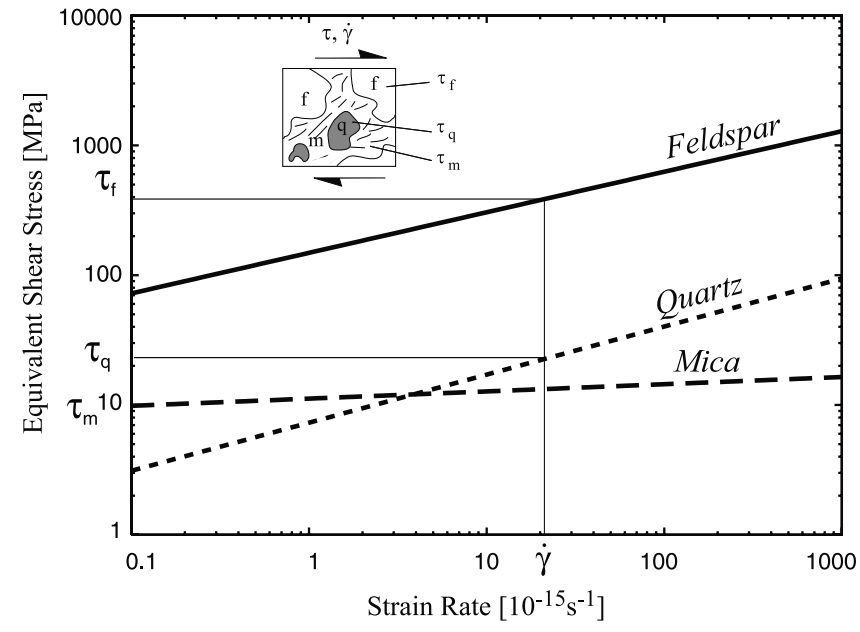

Figure 5. Dislocation creep flow stresses (equation (2)), for feldspar, quartz and mica, as a function of the strain rate, for data of Table 1 and $\mathrm{T}=400^{\circ} \mathrm{C}$. In a REV, shown in inset, the three minerals sustain the same strain rate $\dot{\gamma}$ and the macro shear stress $\tau$ is the sum of the three partial stresses weighted by the phase concentrations.

Ferry, 1994]. The details of the physical mechanisms which permit the water circulation and its use for the reaction are complex and beyond the scope of this paper. However, there are strong field evidences that such a reaction took place and the objective of the rest of this paper is to assess the mechanical consequences of this reaction without further discussions of the availability of fluids.

[25] The mineralogical change, increase in mica concentration and decrease in feldspar proportion, induces a decrease of the REV strength, as reported by Shea and Kronenberg [1993] from experimental results. Figure 5 presents steady state dislocation creep flow stresses of feldspar, quartz and mica at a temperature set to $400^{\circ} \mathrm{C}$ (midcrustal conditions). Feldspar can sustain a shear stress a hundred times larger than mica. Therefore, the activation of the reaction in a REV does lead to a reduction in its shearing strength. It remains now to construct a rheological model with reaction-softening coupled with feldspar fracturing, the task of next section.

\section{Construction of the Rheological Model}

[26] The REV considered is composed of three solid phases: feldspar (f), quartz (q) and white mica (m). The concentration of each phase is defined by the volume occupied by the phase over the total REV volume. This concentration is denoted $C_{\alpha}$, where $\alpha$ stands for feldspar (f), quartz (q) or mica (m). Despite the possible change of volume during metamorphic reactions and the increase in total mass due to the fluids (reaction 1), the three solid phase concentrations satisfy the relation $C_{f}+C_{q}+C_{m}=1$ at any time.

[27] As evidenced from the ETSZ, the main deformation mechanism for feldspar, quartz and mica, except for microfracturing of feldspar, is dislocation creep. Among the micas, biotite has received the most attention in the literature [Kronenberg et al., 1990; Shea and Kronenberg, 
Table 1. Rheological Parameters for Dislocation Creep ${ }^{\mathrm{a}}$

\begin{tabular}{lccc}
\hline \multicolumn{1}{c}{ Parameters } & Feldspar & Quartz $^{\mathrm{c}}$ & $\mathrm{Mica}^{\mathrm{d}}$ \\
\hline $\bar{Q}, \mathrm{~kJ} \mathrm{~mol}^{-1}$ & 238 & 134 & 51 \\
$n$ & 3.2 & 2.7 & 18 \\
$\bar{A}, \mathrm{MPa}^{-n} \mathrm{~s}^{-1}$ & $3.27 \times 10^{-4}$ & $1.16 \times 10^{-7}$ & $1 \times 10^{-30}$ \\
$\beta_{\alpha}$ & 35.8 & 20.1 & 7.7 \\
$\tau_{R \alpha}$ & 9.6 & 1. & 4.5 \\
$\dot{\gamma}_{R \alpha}$ & 1. & 1. & 1. \\
\hline
\end{tabular}

${ }^{\mathrm{a}}$ The three last parameters are dimensionless (see Appendix $\mathrm{A}$ and Table 2).

${ }^{\mathrm{b}}$ From Shelton and Tullis [1981].

${ }^{\mathrm{c}}$ From Koch et al. [1989].

${ }^{\mathrm{d}}$ From Kronenberg et al. [1990] for biotite.

1993] and is selected here, assuming that its rheological properties are not significantly different than those of white mica. The power law relation between the strain rate $\dot{\bar{\gamma}}_{\alpha}$ and the equivalent shear stress $\bar{\tau}_{\alpha}$ for dislocation creep reads

$$
\frac{\dot{\bar{\gamma}}_{\alpha}}{\dot{\bar{\gamma}}_{R \alpha}}=\exp \left[-\beta_{\alpha}\left(\frac{\bar{T}_{o}}{\bar{T}}-1\right)\right]\left(\frac{\bar{\tau}_{\alpha}}{\bar{\tau}_{R \alpha}}\right)^{n_{\alpha}},(\alpha=f, q, m),
$$

in which $\bar{T}_{o}$ and $\bar{T}$ are the characteristic temperature of the lower crust and the temperature at the depth of interest, respectively. The rheological parameters $\dot{\bar{\gamma}}_{R \alpha}, \beta_{\alpha}, \bar{\tau}_{R \alpha}$ and $n_{\alpha}$ correspond to the characteristic strain rate, the activation energy, the characteristic shear stress and the shear stress exponent, respectively. The differences in dislocation creep accommodation for quartz and feldspar, already discussed in previous sections, are accounted for in our rheological model by the different values of the activation energy and the shear stress exponent (Table 1).

[28] Note that in equation (2), as well as in the rest of this paper, a superposed bar indicates a variable with dimension, whereas the absence of superposed bar identifies a dimensionless variable. Any physical variable $\bar{a}$ will thus be replaced by its dimensionless form $a$, which is defined by $a=\frac{\bar{a}}{\bar{a}_{c}}$, where $\bar{a}_{c}$ is the characteristic value of variable $\bar{a}$. The computation of the characteristic values is presented in Appendix A, and the results given in Table 2 .

[29] The next step in constructing the rheological model consists of defining the overall shear stress $\bar{\tau}$ and overall strain rate $\dot{\bar{\gamma}}$ from the partial shear stresses $\bar{\tau}_{\alpha}$ and strain rates $\dot{\bar{\gamma}}_{\alpha}$, for the three solid phases. Theoretically, two endmember associations of these polyphase assemblages are possible: uniform shear stress over the REV or uniform strain rate [Handy, 1990; Tullis et al., 1991; Handy et al., 1999]. For uniform shear stress, the three minerals deform at their own strain rate $\dot{\bar{\gamma}}_{\alpha}$. Our selection of a uniform strain rate is motivated as follows. The large value of the shear stress exponent of mica $\left(n_{m}=18\right.$, Table 1$)$ implies that the mica partial shear stress is approximately constant over four orders of magnitude in strain rate (Figure 5). Therefore, if the three minerals are assumed to sustain the same shear stress, the mica phase will dominate and its strain rate could be unrealistic compared to field observations. Furthermore, the shear stress will be constant (equal to the mica partial shear stress) implying the absence of shear softening due to the feldspar-to-mica reaction. This assumption of uniform shear stress is thus in discrepancy with the reported field observations within the ETSZ. In contrast, with uniform strain rate, the three minerals deform with their own partial shear stress $\tau_{\alpha}$. The activation of the feldspar-to-mica reaction in a REV at a given strain rate does lead to the reduction in its shearing strength, since feldspar flow stress is larger than mica flow stress (Figure 5). Therefore, as a first approximation and for simplicity sake, a homogenous strain rate is assumed within the REV. The overall shear stress $\bar{\tau}$ is then the weighted sum of the three partial shear stresses

$$
\bar{\tau}=\sum_{\alpha=f, q, m} C_{\alpha} \bar{\tau}_{\alpha}
$$

where the three particular values of $\bar{\tau}_{\alpha}$ are defined using the power law creep (equation (2)) with $\dot{\bar{\gamma}}_{\alpha}=\dot{\bar{\gamma}}$.

[30] The progressive replacement of feldspar into white mica defines the time evolution for mica content. As observed within the ETSZ, the initiation of this reaction is strongly dependent upon the brittle fracturing of feldspar grains. The time evolution of mica content should thus be zero as long as feldspar grains are not fractured. The selection of a criterion to detect the fracture of feldspar grains is an open question. One possibility is that microcracks initiated at grain boundaries where dislocation pileup occurs, pointing to a grain-size dependence for the fracture threshold [Mitra, 1978]. The size of the defect necessary for intragranular crack growth is however not known nor the fracture toughness of the mineral. A more pragmatic approach is as follows. Field observations point to a depth-dependence of the minimum stress for microfracturing [Mitra, 1978]. First numerical calculations indicate that this dependence can be approximated by the Mohr-Coulomb criterion with a low friction coefficient of 0.2 [Gueydan et al., 2001]. It is thus assumed in the following that feldspar microfracturing occurs if the partial stress $\bar{\tau}_{f}$ is larger than the lithostatic pressure $\bar{p}$, defined by the overburden weight, times the friction coefficient $\mu$. This brittle activation of the mineralogical change is accounted for via the $\delta$ parameter, which is either one or zero depending on the activation of the Mohr-Coulomb criterion:

$$
\begin{aligned}
& \delta=0 \text { if } \bar{\tau}_{f}+\mu \bar{p}<0, \\
& \delta=1 \text { if } \bar{\tau}_{f}+\mu \bar{p} \geq 0 .
\end{aligned}
$$

[31] The time evolution of mica concentration needs now to be defined to complement our rheological model. We propose here that the mylonitic mica proportion, denoted $C_{m}^{\star}$, acts as an attractor so that the mica concentration rate $\dot{C}_{m}$ is proportional to $\left(C_{m}^{\star}-C_{m}\right)$. The mylonitic mica proportion was documented within the ETSZ and estimated in the range of $0.4-0.5$ (Figure 2). The strain rate $\dot{\gamma}$ controls the deformation of feldspar grains and thus the

Table 2. Characteristic Values for Dimensional Analysis

\begin{tabular}{cccl}
\hline Variable & Units & Value & \multicolumn{1}{c}{ Definition } \\
\hline $\bar{\tau}_{c}$ & $\mathrm{MPa}$ & 2.4 & Shear stress \\
$\bar{t}_{c}$ & $\mathrm{Ma}$ & 14 & Conduction time \\
$\overline{\dot{\gamma}}_{c}$ & $\mathrm{~s}^{-1}$ & $2.2 \times 10^{-15}$ & Strain rate \\
$\bar{d}$ & $\mathrm{~km}$ & 20 & Length \\
$\bar{T}_{c}$ & ${ }^{\circ} \mathrm{K}$ & 800 & Temperature \\
$\bar{v}_{c}$ & $\mathrm{~mm} \mathrm{a}^{-1}$ & 1.4 & Velocity \\
\hline
\end{tabular}


rate of the reaction feldspar-to-mica. The transient evolution of mica proportion can thus be expressed in a dimensionless form as

$$
\dot{C}_{m}(t)=\delta(t) \varphi \dot{\gamma}(t)\left(C_{m}^{\star}-C_{m}(t)\right)
$$

where $t$ is the dimensionless time. The scalar $\varphi$ corresponds to an amplitude factor of the reaction kinetics and is referred to hereafter as the kinetics factor. The physical significance of $\varphi$ is explained as follows. Assuming a constant strain rate and $\delta=1$, the expression of $C_{m}(t)$ derived from (5) reads:

$$
C_{m}(t)=C_{m}^{\star}-\left(C_{m}^{\star}-C_{m}^{0}\right) \exp (-\varphi \dot{\gamma} t) \quad(\dot{\gamma}=\mathrm{cst})
$$

where $C_{m}^{0}$ is the initial mica concentration $(10 \%$ as observed within the ETSZ). Therefore, the product $\varphi \dot{\gamma}$ is the inverse of the dimensionless characteristic reaction time, denoted $t_{R}$ :

$$
t_{R}=1 / \varphi \dot{\gamma} \quad(\dot{\gamma}=\mathrm{cst})
$$

This characteristic time is not constant in what follows since $\dot{\gamma}$ varies with time. But this interpretation will be found useful during the localization analysis presented in section 6 .

\section{Rheological Envelope}

[32] The consequence of reaction-softening controlled by a pressure-sensitive criterion for the rheological stratification of the lower crust is explored in this section. It is assumed that $80 \%$ of initially present feldspar could be transformed into mica. It results in a mylonitic mica content $C_{m}^{\star}$ of 0.5 , as it is observed in thin sections within the ETSZ.

[33] The rheological envelopes are constructed traditionally assuming a homogeneous stretching mode of deformation at a rate set to the reference strain rate $\dot{\bar{\gamma}}_{c}$ (Table 2). We adopt the stretching mode of deformation despite the simple shear studied in section 6. The temperature distribution is defined by a temperature of $800^{\circ} \mathrm{C}$ at the Moho and a gradient of $30^{\circ} \mathrm{C} \mathrm{km} \mathrm{km}^{-1}$. These parameters are used to compute the equivalent shear stress, according to equation (2), through the $20-\mathrm{km}$-thick lower crust. The results are reported in Figure 6 for the protolith material $\left(C_{m}=0.1, C_{f}=\right.$ 0.5 and $\left.C_{q}=0.4\right)$, the mylonite $\left(C_{m}=0.5, C_{f}=0.1\right.$ and $C_{q}=$ $0.4)$ and a single mineral, feldspar. Note that the dimensionless $y$-coordinate ranges from 0 to 1 in the lower crust corresponding to depths between $30 \mathrm{~km}$ (the Moho) and 10 $\mathrm{km}$ (upper crust contact), as shown in Figure 4. The MohrCoulomb criterion which controls the onset of the feldsparto-mica reaction is also plotted, using a lithostatic pressure gradient of $27.5 \mathrm{MPa} \mathrm{km}{ }^{-1}$.

[34] For a friction coefficient $\mu$ set to 0.6 , the MohrCoulomb criterion is met at the depth of point $\mathrm{A}(y=0.68$, $\tau_{f A}+\mu p_{A}=0$ ). Decreasing the value of the friction coefficient leads to the triggering of the metamorphic reaction at greater depths (point $\mathrm{B}$ at $y=0.48$ for $\mu=$ 0.2 ). Concentrating on the value $\mu=0.6$, the feldspar-tomica reaction is inhibited for depth larger than depth of point A. At these depths, the strength is therefore governed by the protolith strength. In contrast, assuming a completed

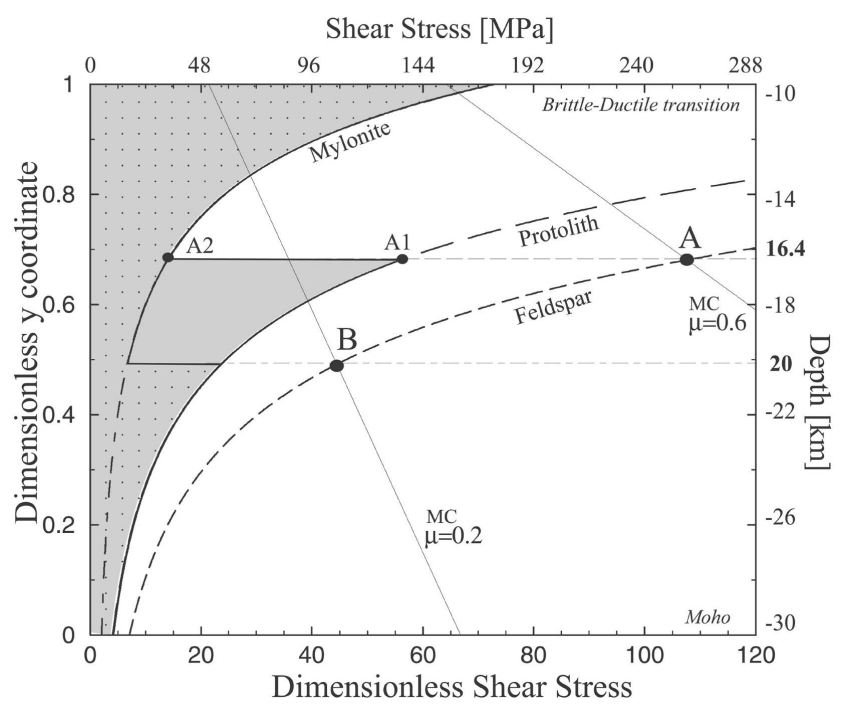

Figure 6. The equivalent shear stress as a function of depth, for a given strain rate $\left(2.2 \times 10^{-15} \mathrm{~s}^{-1}\right)$, is plotted for feldspar, the protolith $\left(C_{f}=0.5, C_{q}=0.4\right.$ and $\left.C_{m}=0.1\right)$ and for a mylonite of composition: $C_{f}=0.1, C_{q}=0.4$ and $C_{m}=$ 0.5 . Two rheological envelopes for a completed feldspar to mica reaction are plotted for two values of the friction coefficient: light shaded area for $\mu=0.6$ and doted shaded area for $\mu=0.2$.

reaction $\left(C_{m}=C_{m}^{\star}\right)$, the strength of the lower crust at shallow depths is governed by the mylonitic flow stress (Figure 6). The model of reaction-softening controlled by a pressure sensitive criterion thus leads to a stress drop at a depth of $16.4 \mathrm{~km}$ and $20 \mathrm{~km}$, for $\mu$ of 0.6 and of 0.2 , respectively. At these depths, the lower crust strength is reduced by a factor of three compared to the protolith value (Figure 6).

[35] The depth of the stress reduction is controlled by the value of the friction coefficient $\mu$. This stress reduction should result in strain localization at midcrustal depths. However, this tendency toward localization develops in the transient regime, during the feldspar to mica reaction (evolution from point $A_{1}$ to point $A_{2}$, Figure 6). Steady states rheological envelopes therefore cannot capture the strain localization process, which is documented next with a numerical analysis of the simple shearing of the lower crust.

\section{Localization Analysis}

[36] It is shown in this section that reaction-softening controlled by a pressure sensitive criterion results in strain localization at a depth close to $15 \mathrm{~km}$ during rapid extension of the upper crust. The objective is also to identify the parameters which control the depth, the width and the timing of the shear zone. These results are based on a finite element solution of the 1-D simple shear of the lower crust, motivated by the structural model presented in Figure 4c.

\subsection{1-D Model Problem}

[37] At early stages of extension, the Alpine Corsica continental crust was characterized by an active set of conjugate normal faults in the upper crust, and an active low-angle east-dipping shear zone (ETSZ) in the middle 

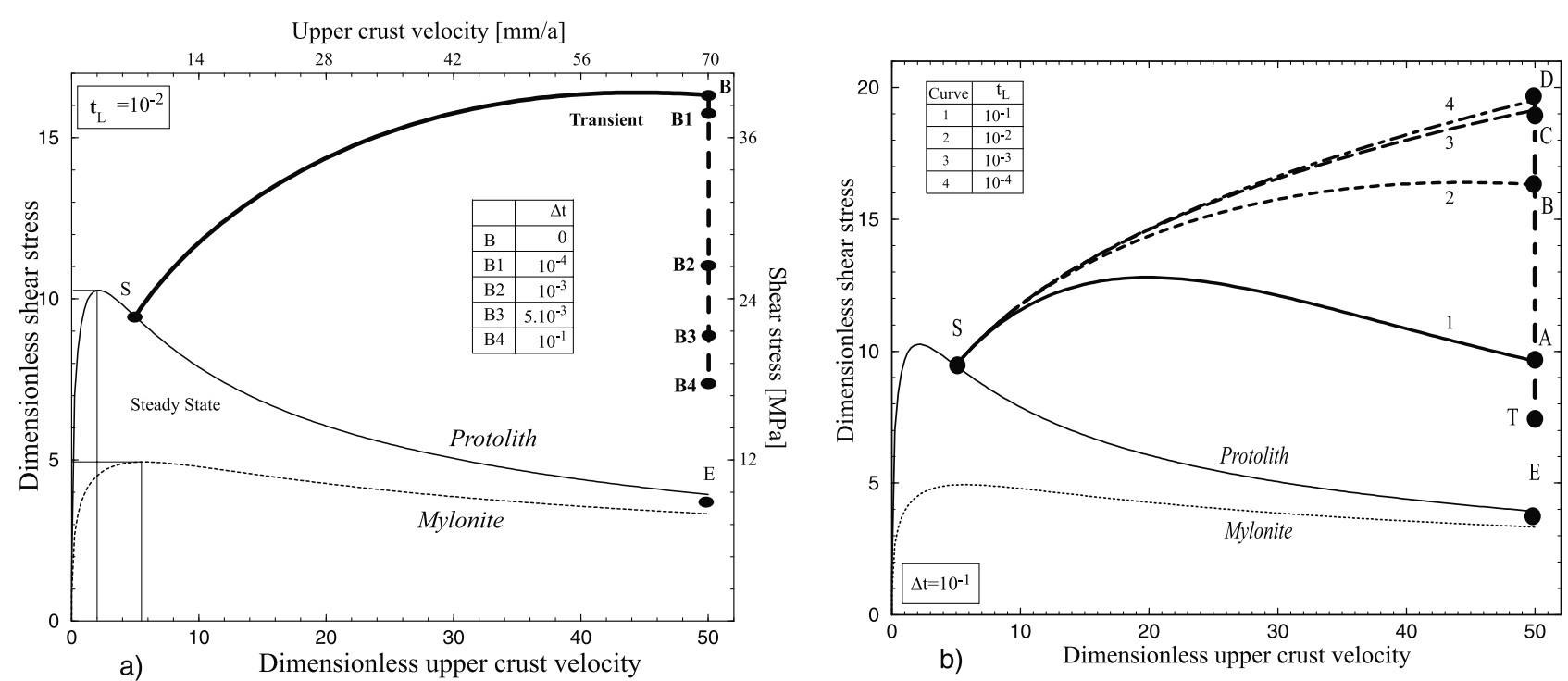

Figure 7. Dimensionless equivalent shear stress as a function of the upper crust gliding velocity for steady state flow (thin solid curve for the protolith and thin-dashed curve for the mylonite). In a), the transient evolution from $\mathrm{S}$ to $\mathrm{B}$, reached after $t_{L}=10^{-2}(140 \mathrm{ka})$, is plotted as a thick solid curve. The velocity is kept constant at $V=50$ during different time interval $\Delta t$, as presented in inset, and leads to a decrease of the shear stress from point B to point B4 (thick dashed curve). This evolution is toward the steady state attractor, point $\mathrm{E}$. In b), the shear stress enhancement due to the increase of the upper crust velocity, is plotted for different time lapses $t_{L}$. The stress trajectories, from $\mathrm{S}$ to $\mathrm{A}, \mathrm{S}$ to $\mathrm{B}, \mathrm{S}$ to $\mathrm{C}$ and $\mathrm{S}$ to $\mathrm{D}$ are obtained for $t_{L}$ equal to $10^{-1}, 10^{-2}, 10^{-3}$ and $10^{-4}$, respectively. Point $\mathrm{T}$ is reached from either $\mathrm{A}$, $\mathrm{B}, \mathrm{C}$ or D after a $\Delta t$ of $10^{-1}$, at a constant velocity of 50 .

crust. At a large distance from this graben, section $\mathrm{AA}^{\prime}$ of Figure $4 \mathrm{~b}$, the upper crustal material is not deforming and is assumed to glide rigidly over the lower crust. Concentrating on section $\mathrm{AA}^{\prime}$, the overall deformation of the lower crust is well approximated by a 1-D flow corresponding to simple shear (Figure 4c).

[38] The heat equation is solved through the whole crust thickness $(30 \mathrm{~km})$, with radiogenic heat production and shear heating $(\tau \dot{\gamma})$. Mechanical equilibrium (constant shear stress $\tau$ ) is also enforced but only over the lower crust. The complete set of equations is found in the work of Gueydan et al. [2001] and the solution procedure in the study by Gueydan [2001]. The lower crust is divided into 300 Lagrangian finite elements with 3 nodes. This number was found to be sufficient to capture strain localization. The thermal and velocity boundary conditions are as follows. The velocity is set to zero at the Moho and is denoted $V$ at the upper crust contact. The imposed value of $V$ is a function of time defining the transient regime. The imposed heat flux through the Moho is set to $30 \mathrm{~mW} \cdot \mathrm{m}^{-2}$ and the surface temperature is equal to $300^{\circ} \mathrm{K}$. Note that the characteristic time $\bar{t}_{c}$ for heat conduction over the $20-\mathrm{km}-$ thick lower crust is $14 \mathrm{Ma}$ (see Appendix A and Table 2).

\subsection{Steady States and Transient Regime}

[39] Stationary simple shear solutions over the whole continental lower crust are first presented, assuming a constant concentration of the three solid phases. The evolution with time of the shear flow is then explored during a rapid increase of the upper crust gliding velocity, using the steady states as initial conditions. This increase should be seen as a consequence of a change in extension rate of the upper crust. It is during that evolution that the protolith to mylonite transformation should take place and the tendency toward localization capture. A description of the steady states and transient regimes in the lower crust sustaining simple shear is given by Gueydan et al. [2001] for a grainsize sensitive rheology. The novelty of the present study is the strain localization observed during the transient regime due to the destabilizing role played by reaction-softening initiated by feldspar fracturing.

[40] The initial and the final stationary solutions are plotted in Figure $7 \mathrm{a}$ as the protolith $\left(C_{f}=0.5, C_{q}=0.4\right.$ and $\left.C_{m}=0.1\right)$ and mylonite curve, respectively. The second is plotted assuming that the transformation took place over the whole lower crust, using a mylonitic composition of: $C_{f}=0.1, C_{q}=0.4$ and $C_{m}=0.5$. The influence of the final mica concentration will be explored at a later stage of this section. The shear stress is first an increasing function of the upper crust velocity and has a maximum which is larger for the protolith than for the mylonite, in view of the larger mica concentration in the latter. The shear stress is a decreasing function of the velocity beyond that maximum because of shear heating at the Moho contact [Gueydan et al., 2001].

[41] The transient regime results from a change in extension rate of the upper crust starting from a steady state. The gliding velocity of the upper crust is first increased linearly during a time lapse denoted $t_{L}$ from its initial steady state value $\mathrm{V}=5$ to $\mathrm{V}=50$ (Points $\mathrm{S}$ to $\mathrm{B}$ in Figure $7 \mathrm{a}$ ). Second, the velocity is kept constant at $\mathrm{V}=50$ during a time interval denoted $\Delta t$. From $\mathrm{S}$ to $\mathrm{B}$, the increase in the gliding velocity results in an increase in the equivalent shear stress because of the strain rate sensitivity of the flow law (equation (2)). This change occurs with little variation in temperature. 

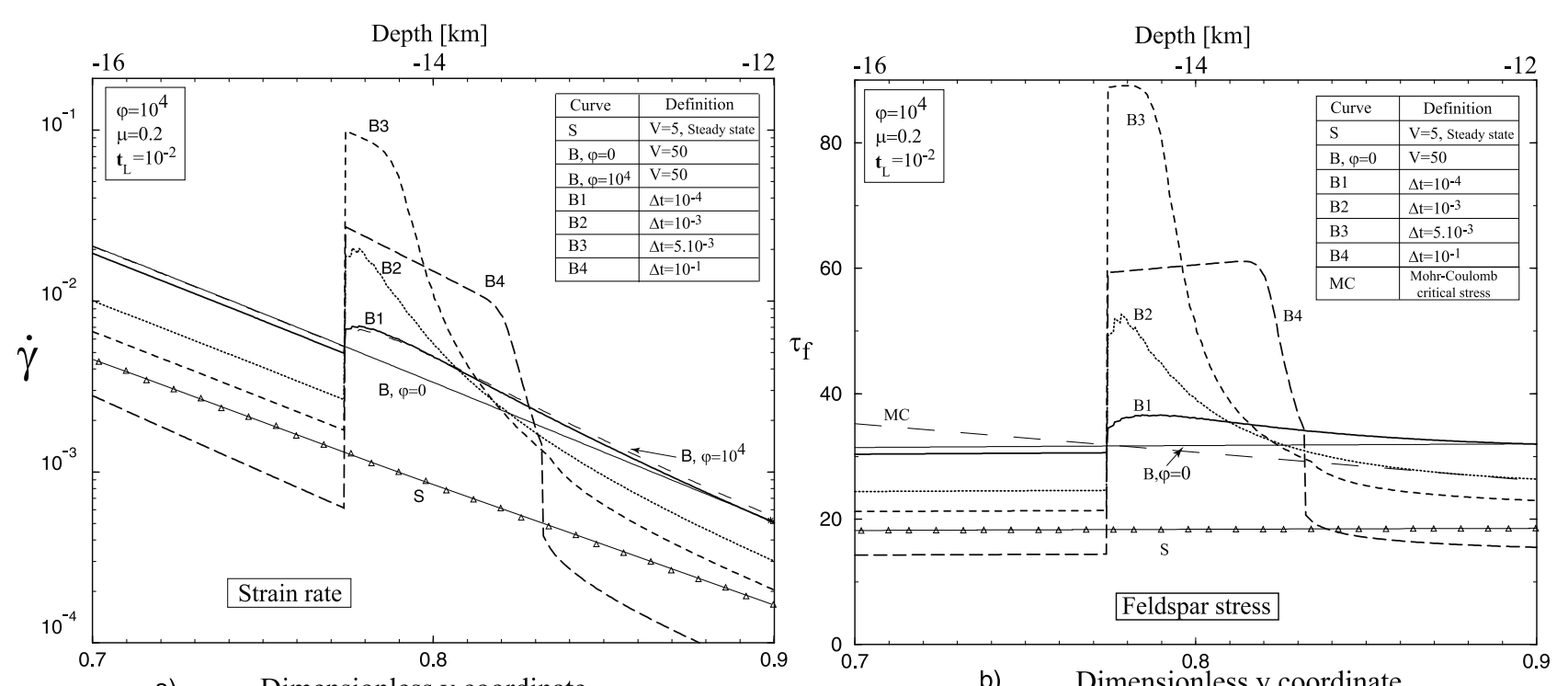

a) Dimensionless y coordinate

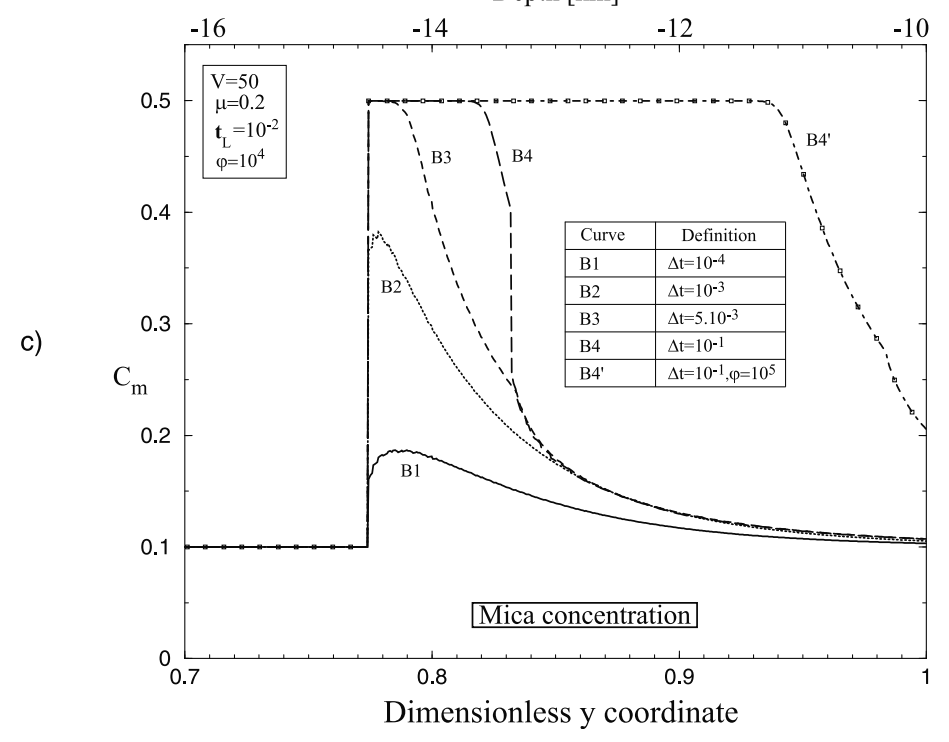

Figure 8. Strain rate (a), feldspar shear stress (b) and mica concentration (c) profiles in the upper part of the lower crust for steady state $(\mathrm{V}=5)$ and different transient states (B to $\mathrm{B} 4$ of Figure $7 \mathrm{a})$. In $\mathrm{b})$, the Mohr Coulomb (MC) critical shear stress for the onset of the metamorphic reaction is also plotted (thin long-dashed line) for a friction coefficient of 0.2 . In c), for state B4, the mica concentration is plotted both for $\varphi=10^{4}$ (curve B4) and $\varphi=10^{5}$ (curve B4').

Points B1 to B4 are obtained after a $\Delta t$ varying from $10^{-4}$ to $10^{-1}$, respectively (inset of Figure 7 ). During $\Delta t$, thermal equilibrium leads to an increase in temperature near the Moho at depths close to $25-30 \mathrm{~km}$ (large shear heating due to the large value of the strain rate at that depth). Therefore, during this time interval $\Delta t$, temperature effects become important, resulting in a reduction of the overall equivalent shear stress. The evolution from point $\mathrm{B}$ is toward point $\mathrm{E}$ which is the steady state attractor obtained for a reaction over part of the lower crust. This attractor has to be between the protolith and mylonite steady state solutions (Figure 7a).

[42] To appreciate the role of the time lapse $t_{L}$ during which the velocity is changed, several simulations have been conducted for $t_{L}$ of $10^{-1}$ to $10^{-4}$ (points $\mathrm{A}$ to $\mathrm{D}$ on Figure $7 \mathrm{~b}$ ). The shorter $t_{L}$, the larger is the stress increase.
The adiabatic limit is seen to be approached for a $t_{L}$ of $10^{-4}$ to $10^{-3}$ (points $\mathrm{D}$ and $\mathrm{C}$ ). For $t_{L}$ set to $10^{-1}$ (point $\mathrm{A}$ ) temperature effects are sufficient to counter balance the strain rate sensitivity of the flow and to lead to a reduction in stress. This is again because of an increase in temperature near the Moho due to shear heating.

[43] Having now a general understanding of the long term evolution of the simple shear flow, we concentrate next on the details of the strain rate profiles to detect the tendency for strain localization.

\subsection{Strain Localization}

[44] The strain rate, the feldspar partial stress and the mica concentration are plotted as a function of depth in Figure 8 for transient states B $\left(t_{L}=10^{-2}\right)$ to $\mathrm{B} 4\left(\Delta t=10^{-1}\right)$ presented 
in the previous subsection (Figure 7a). The dimensionless $y$-coordinate in this series of figures ranges from 0.7 to 0.9 or 1 corresponding to the upper part of the lower crust $(y=1$ at the upper crust contact). The kinetics parameter $\varphi$ for the metamorphic reaction is set to $10^{4}$, except for one simulation. It is assumed that $80 \%$ of the present feldspar in the protolith could be transformed into mica $\left(C_{m}^{\star}=0.5\right)$. The role played by these two parameters $\left(\varphi\right.$ and $C_{m}^{\star}$ ) in the localization process is documented in the next subsection.

\subsubsection{Onset of Strain Localization}

[45] If the metamorphic reaction is inhibited $(\varphi=0)$, the increase in the gliding velocity of the upper crust from $\mathrm{V}=$ 5 to 50 (point $\mathrm{S}$ to point $\mathrm{B}$ in Figure $7 \mathrm{a}$ ) during $t_{L}=10^{-2}$ induces an increase in the strain rate by an order of magnitude (curve B, $\varphi=0$, Figure $8 \mathrm{a}$ ).

[46] The strain rate is an increasing function of depth which is explained by the constant equivalent shear stress (mechanical equilibrium) and the temperature sensitivity of the flow law (equation (2)). However, if the reaction takes place (curve $\mathrm{B}, \varphi=10^{4}$, Figure $8 \mathrm{a}$ ), the strain rate is discontinuous at $y=0.77$ (depth of $14.6 \mathrm{~km}$ ) and presents a sharp increase above that depth compared with the strain rate obtained in the absence of metamorphic reaction. This tendency is confirmed in time (curves B1 and B2): a jump in strain rate by an order of magnitude occurs at $y=0.77$. Away from that region, the strain rate is decreased compared to curve B. This can be explained as follows. The strain rate is defined as the derivative of the lower crust velocity with respect to the $y$-coordinate. Therefore, the average strain rate over the lower crust is the upper crust gliding velocity $\mathrm{V}$ with respect to the Moho. Since V remains constant during $\Delta t$, a region of large strain rate must coexist with a region of low strain rate to enforce this condition of constant average strain rate over the whole lower crust. The tendency toward localization continues until $\Delta t=5.10^{-3}$ (curve $\mathrm{B} 3$ ) and the increase in strain rate in the shear zone is then of two orders of magnitude compared to the outside. Beyond that time, the maximum strain rate decreases and the thickness of the shear zone increases (curve B4), because of thermal equilibrium (temperature increase near the Moho leading to a decrease in the shear stress and thus in the strain rate).

[47] In summary, two stages characterize the onset of localization: first, an increase in strain rate in a narrow zone and, second, the reduction in strain rate coeval with the broadening of the shear zone. The shear zone is defined by an increase of strain rate by at least two orders of magnitude. The depth of the upper and lower boundaries of the shear zone are controlled by the activation and the deactivation of the metamorphic reaction, as documented in the following subsection.

\subsubsection{Depth and Width of the Shear Zone Controlled} by the Feldspar-to-Mica Reaction

[48] The feldspar partial stress is presented in Figure $8 \mathrm{~b}$ as a function of the $y$ coordinate. The critical shear stress according to the Mohr-Coulomb (MC) criterion (equation (4)), below which no mineralogical change can take place, is also plotted. The value of the friction coefficient is set to 0.2 because no strain localization is observed for larger values of $\mu$. Moreover, this low value of the friction coefficient was found to approximate the depth-dependence of feldspar fracturing [Gueydan et al., 2001].
[49] Initially, at $\mathrm{V}=5$, the feldspar partial shear stress is below the critical MC shear stress (curve S). If no metamorphic reaction takes place, this condition is not respected at time $t_{L}=10^{-2}$ (curve B, $\varphi=0$ ): the partial shear stress in the region $0.77<y<1$ is larger than the MC value (Figure $8 \mathrm{~b})$. Owing to our rheological model, a metamorphic reaction must therefore take place in this region $(\delta=1$, equation (5)). This is demonstrated in Figure $8 \mathrm{c}$ in which the mica concentration is discontinuous at the depth of 0.77 at time $\Delta t=10^{-4}$ (curve B1). At this time, the metamorphic reaction occurs over the whole upper part of the lower crust $(y>0.77)$. Note that the feldspar partial shear stress is larger in this zone (Figure 8b).

[50] This is justified by recalling that the macro stress is constant over the whole lower crust but results pointwise from the sum of the partial stresses weighted by the phase concentrations. Reducing the phase concentration of feldspar leads to an increase of its partial stress such that the phase contribution to the representative volume element is maintained to the level required for mechanical equilibrium. The tendency for the strain to localize leads to a reduction in strain rate away from the zone of reaction resulting in a decrease in the feldspar partial stress outside the reaction zone (curve B2, Figure 8b). For example, the feldspar partial stress profile is tangent to the MC line at $\Delta t=$ $10^{-3}$ (curve B2) and intersects this MC critical stress at $\mathrm{y}=$ 0.83 , at time $\Delta t=5 \cdot 10^{-3}$ (curve B3). From then on, the metamorphic reaction takes place within the shear zone defined by the coordinates 0.77 and 0.83 corresponding to a thickness of $1.2 \mathrm{~km}$. This thickness does not appear to change with time beyond $\Delta t=5 \cdot 10^{-3}$.

[51] Note that for the same value of the friction coefficient $(\mu=0.2)$, the depth at which metamorphic reaction occurs is $14.6 \mathrm{~km}(\mathrm{y}=0.77)$ whereas it is $20 \mathrm{~km}$ in the rheological envelope (Figure 6). This discrepancy is explained by the difference in deformation modes. The lower crust sustains a stretching mode of deformation (constant strain rate) for the rheological envelope construction, whereas simple shear mode of deformation is considered (constant equivalent shear stress) in this localization analysis. The difference in deformation modes induces a difference in stress level within the lower crust (higher values for the stretching mode of deformation) and therefore different depths for the initiation of Mohr-Coulomb criterion.

[52] In summary, the lower boundary of the shear zone is the depth at which the metamorphic reaction is triggered. This depth is used here to define the depth of the shear zone. The upper boundary corresponds to the depth where the pressure-sensitive criterion is deactivated due to a decrease in strain rate outside the shear zone during the localization process. The predicted depth $(14.6 \mathrm{~km})$ and width $(1.2 \mathrm{~km})$ of the shear zone are consistent with the field observations from the ETSZ. This correlation validates the assumption that the reaction coupled with microfracturing is the relevant destabilizing factor for the particular example of the East Tenda Shear Zone.

\subsubsection{Shear Zone Broadening}

[53] It remains now to explain the broadening of the strain rate distribution within the shear zone. This broadening occurs between $\Delta t=5.10^{-3}$ and $10^{-1}$ (curve B3 to B4, Figure $8 \mathrm{a})$. The depth-range at which the reaction is completed $\left(C_{m}=C_{m}^{\star}\right)$ broadens with time to reach 

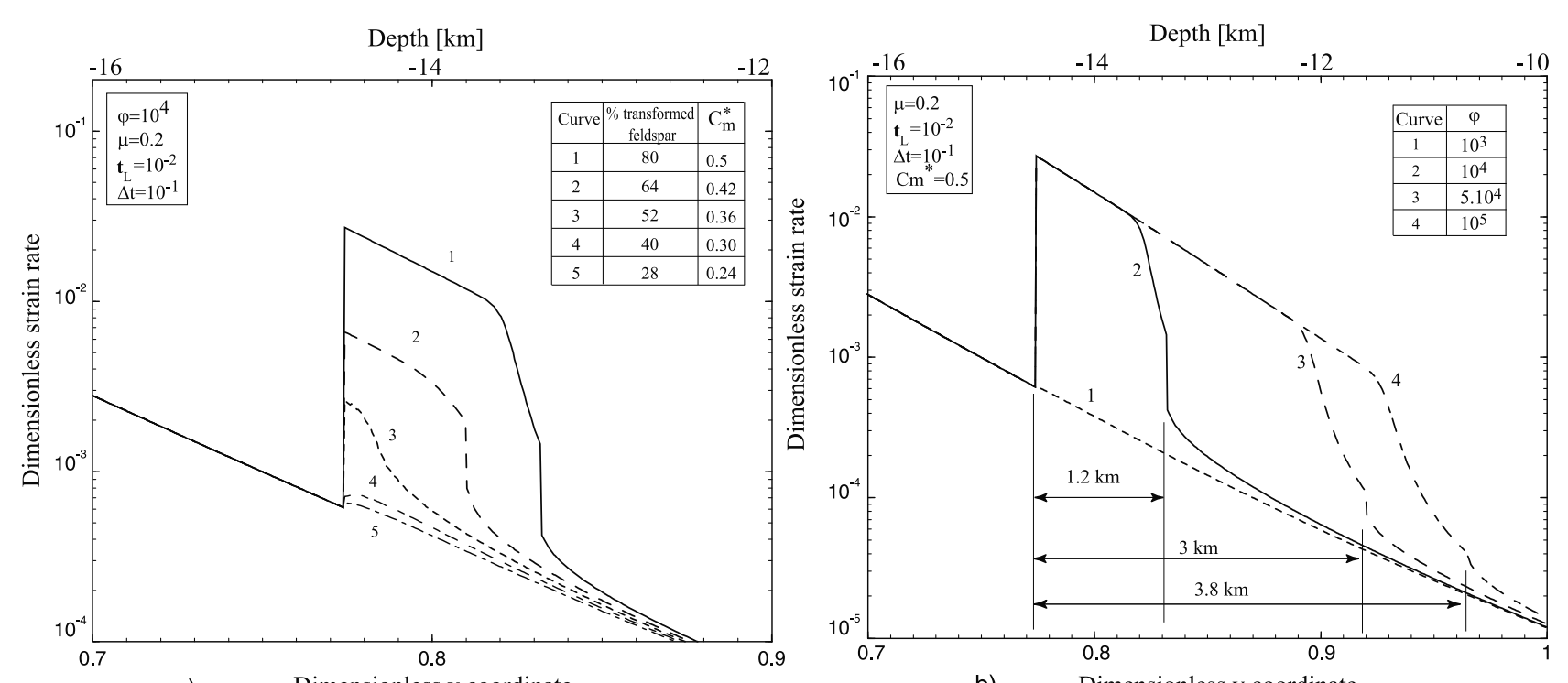

a)

Dimensionless y coordinate

b)

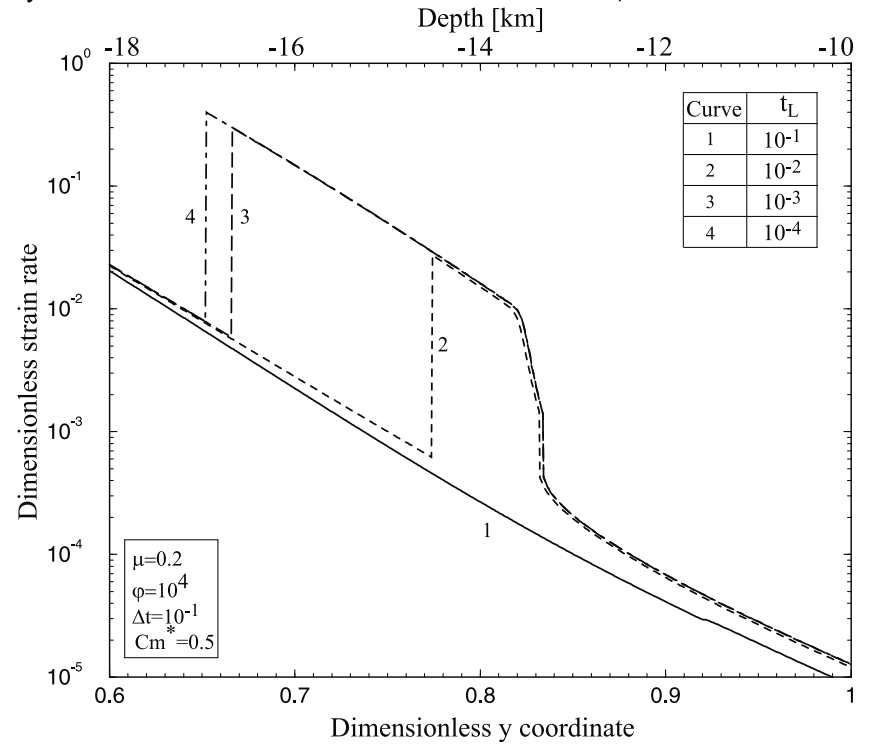

Figure 9. Strain rate profiles in the upper part of the lower crust for different values of $C_{m}^{\star}(\mathrm{a}), t_{L}(\mathrm{~b})$ and $\varphi$ (c). In a), curves 1 to 5 are plotted for $C_{m}^{\star}$ decreasing from 0.5 to 0.24 . In b), curves 1 to 4 are for $\varphi$ increasing from $10^{3}$ to $10^{5}$. In c), curves 1 to 4 are for $t_{L}$ between $10^{-1}(1.4 \mathrm{Ma})$ and $10^{-4}(1.4 \mathrm{ka})$, respectively. The stress-velocity curves corresponding to these values of $t_{L}$ are presented in Figure $7 \mathrm{~b}$.

approximately the width of $1.2 \mathrm{~km}$ at $t=10^{-1}$ (curve B4, Figure $8 \mathrm{c}$ ). To understand the decrease in strain rate during the shear zone broadening, one should recall that the destabilizing effect is the feldspar to mica reaction. As it ceases (reaction completed), the material has a positive strain rate sensitivity ( $\tau$ increases if $\dot{\gamma}$ increases). The adjacent material, where the reaction is still ongoing, has a negative strain rate sensitivity, characteristic of the destabilizing effect. Consequently, the shear zone tends to broaden instead of narrowing. More precisely, the strain rate ceases to increase at $\mathrm{y}=0.77$ and the width of the strain rate profile increases to occupy the whole shear zone at $\Delta t=$ $10^{-1}$ (curve B4, Figure 8a). It should be added that at that time, the general trend for the strain rate profile is to decrease over the upper part of the lower crust. This is due to large shear heating at $25-30 \mathrm{~km}$ depth, leading to an increase of the strain rate at these depths. To enforce the condition of constant average strain rate over the lower crust, this increase in strain rate near the Moho must be counter balanced by a decrease of $\dot{\gamma}$ at shallower depths.

\subsection{Parametric Study: Depth and Width of the Shear Zone}

[54] The depth and width of the shear zone are now shown to be controlled by the percentage of feldspar transformed into mica, the kinetics of the metamorphic reaction and the time lapse $t_{L}$.

\subsubsection{Percentage of Transformed Feldspar and the Shear Zone Width}

[55] As observed within the ETSZ, $50 \%$ to $80 \%$ of feldspar can be transformed into white mica in the mylonitic foliation $\left(C_{m}^{\star}=0.35\right.$ to 0.5$)$. Figure 9 a presents the strain 
rate profiles in the upper part of the lower crust, with $t_{L}$ and $t$ set to $10^{-2}$ and $10^{-1}$, for different values of the percentage of feldspar transformed into mica. A decrease of the mylonitic mica concentration $C_{m}^{\star}$ leads to a decrease of the maximum in strain rate and a decrease in the width of the shear zone. The depth at which the metamorphic reaction is triggered remains unchanged.

[56] The decrease in the magnitude of strain rate in the shear zone with the decrease in $C_{m}^{\star}$ is explained by the destabilizing role of the feldspar to mica reaction. The more mica is produced, the more the shear zone strength is reduced and the more intense is the strain localization. For example, if $64 \%$ of feldspar is transformed into mica in the shear zone (curve 2) the maximum strain rate is divided by a factor of two compared to the result for $C_{m}^{\star}=$ 0.5. Furthermore, for a percentage of transformed feldspar in the shear zone smaller than $50 \%\left(C_{m}^{\star}<0.3\right)$ no strain localization is observed.

\subsubsection{Kinetics Factor and Shear Zone Width}

[57] Strain rate profiles for $\varphi=10^{3}, 10^{4}, 5.10^{4}$ and $10^{5}$, with $t_{L}$ and $\Delta t$ set to $10^{-2}$ and $10^{-1}$ respectively, are presented in Figure 9b. For $\varphi=10^{3}$ (curve 1), no strain localization is observed. For larger values of $\varphi$, the upper boundary of the shear zone after the same $\Delta t$ is shifted toward the upper crust contact $(y=1)$. Increasing $\varphi$ leads to an increase in the width of the shear zone since its lower boundary is not influenced. For $\varphi=10^{5}$ (curve 4), the thickness of the shear zone reaches a value of $3.8 \mathrm{~km}$, corresponding to three times the thickness obtained for $\varphi=$ $10^{4}$ (curve 2).

[58] To explain this trend, one should recall that during localization the feldspar partial stress drops outside the shear zone stopping the metamorphic reaction at shallow depths (Figure $8 \mathrm{~b}$ ). Feldspar-to-mica reaction can thus play a destabilizing role during a $\Delta t$ lower than $10^{-2}$, a time interval during which the feldspar partial stress is above the MC threshold. The faster the reaction takes place, the wider the zone where this reaction propagates prior to the stress drop. The reaction time $t_{R}$, which controlled the amount of reaction, is locally governed by the product $\varphi \dot{\gamma}$ so that $t_{R}=$ $1 / \varphi \dot{\gamma}$. Increasing the kinetics factor for the same strain rate leads to a faster reaction which can then be completed over a wider zone during $\Delta t$. This is seen in Figure $8 \mathrm{c}$ where the zone of completed transformation for $\varphi=10^{5}$ (curve B4') reaches $\mathrm{y}=0.94$, corresponding to a shear zone thickness increase by a factor of three compared to the thickness obtained for $\varphi=10^{4}$.

[59] The kinetics factor $\varphi$ thus controls the position of the upper boundary of the shear zone and therefore its width. Moreover, this parameter has a strong influence on the onset of localization. Setting $\varphi$ to any value below $10^{3}$ prohibits strain localization.

\subsubsection{Time Lapse $t_{l}$ and Shear Zone Depth}

[60] Strain rate profiles are plotted in Figure $9 \mathrm{c}$ for different values of $t_{L}$ ranging from $10^{-4}$ to $10^{-1}$, at the time $\Delta t=10^{-1}$. The stress-velocity curves corresponding to these loading parameters have been already discussed (Figure 7b).

[61] Reducing $t_{L}$ leads to an increase of the depth of the shear zone since the lower boundary of the shear zone moves from $\mathrm{y}=0.77$ for $t_{L}=10^{-2}$ to $\mathrm{y}=0.64$ for $t_{L}=10^{-4}$. This trend is explained by the increase of the equivalent

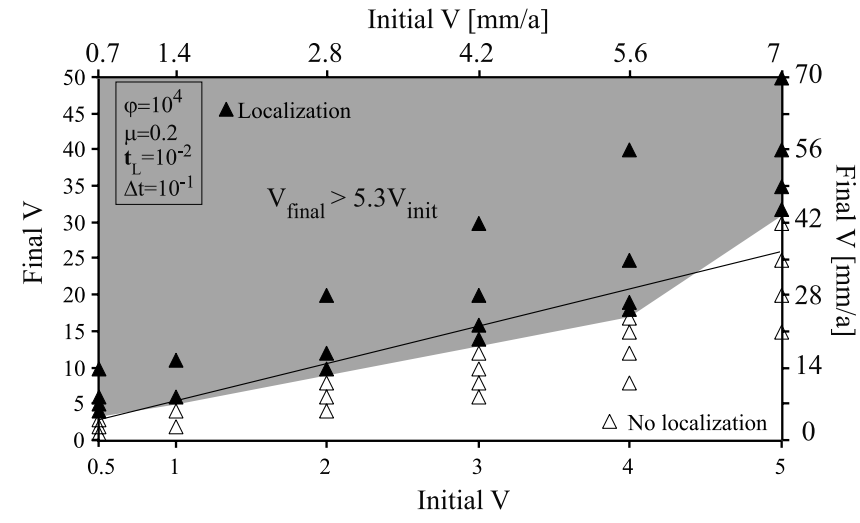

Figure 10. Conditions for localization inferred from different values of the initial and final velocities of the upper crust, after $t_{L}=10^{-2}$ and $\Delta t=10^{-1}$. Open triangles marks the absence of localization whereas localization is detected for solid triangles. The boundary between the localization (shadowed area) and the no-localization region (clear area) is approximated by a straight line of equation: $V_{\text {final }} \simeq 5.3 V_{\text {initial }}$. The final amount of mica $C_{m}^{\star}$ and the kinetic parameter $\varphi$ are set to 0.5 and $10^{4}$, respectively.

shear stress at the end of the velocity change, as presented in Figure $7 \mathrm{~b}$. The shorter $t_{L}$, the larger is the stress increase and the deeper is the Mohr-Coulomb criterion triggered.

[62] For large values of $t_{L}$, no strain localization is observed (curve $1, t_{L}=10^{-1}$, Figure $9 \mathrm{c}$ ). This is again explained by the stress changes during $t_{L}$. The stress increase during $t_{L}=10^{-1}$ is minor (curve 1 of Figure 7b) and the feldspar partial stress is greater than the MC stress for reaction only for $y$ greater than 0.92 . However, the strain rate is very low in this region close to the upper crust contact, preventing any tendency for the reaction to develop. The mica concentration remains close to the original $10 \%$ and the mechanical properties of this area remain nearly unaffected after $\Delta t=10^{-1}$ at which the strain rate profile is plotted in Figure 9c.

[63] Interestingly, the upper boundary of the shear zone at $y=0.83$ is little affected by the selection of the time lapse $t_{L}$. The product $\varphi \dot{\gamma}$ controls the depth of this upper boundary as explained above.

\subsection{Conditions for Localization}

[64] The role of the initial and the final gliding velocities of the upper crust on the localization process is now explored. These two velocities $\left(V_{\text {init }}, V_{\text {final }}\right)$ are changed to find if strain localization occurs. Results are presented in Figure 10, which is partitioned into two regions. In the shadowed region (solid triangles) localization has been detected whereas the clear region (open triangles) marks the absence of localization. Localization is said to occur if the strain rate is locally increased by at least two orders of magnitude with respect to the steady state strain rate, as in the results presented previously. Final velocities as low as $1 \mathrm{~cm} \mathrm{a}^{-1}$ could lead to localization, if the initial velocity is close to $2 \mathrm{~mm} \mathrm{a}^{-1}$. For large values for the initial velocity such as $7 \mathrm{~mm} \mathrm{a}^{-1}$, localization occurs unless the final velocity is below $4 \mathrm{~cm} \mathrm{a}^{-1}$, which is $60 \%$ of the velocity considered in previous sections. 


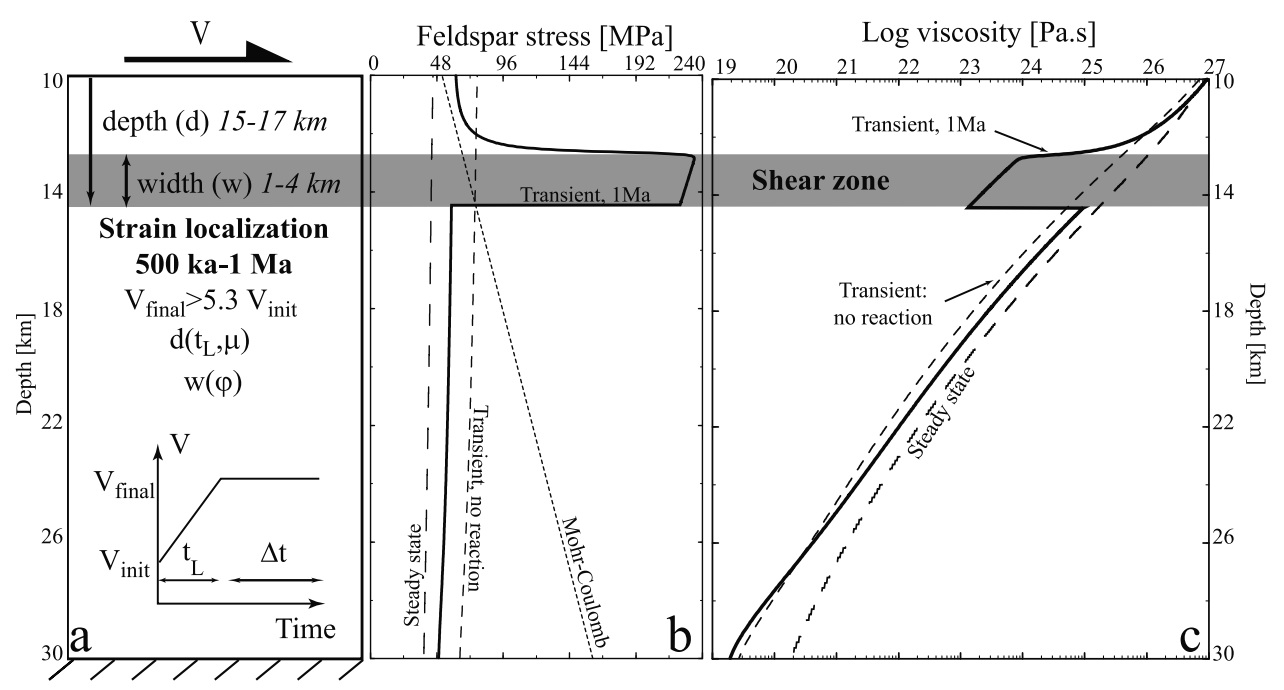

Figure 11. A summary of the results and of the proposed model. In a), the 1-D simple shear problem is presented with the position of the localized shear zone and the change in velocity of the gliding upper crust in inset. In b) and c), the feldspar partial stress and the $\log$ of the secant viscosity $\eta=\tau / \dot{\gamma}$ are plotted over the whole lower crust thickness, respectively.

[65] It is proposed to approximate the boundary between the localization and no localization regions by a straight line (solid line, Figure 10). Localization can then be said to require a final velocity at least approximately five times the initial velocity:

$$
V_{\text {final }}>5.3 V_{\text {init }}
$$

A word on the relevance of these findings for regions in active extension is now in order. In such regions, the GPS horizontal velocities are estimated to range between 1 and $4 \mathrm{~cm} \mathrm{a}^{-1}$. These velocities should be related to our final velocity which is relative to the Moho. In the absence of any information on the flow at that depth it is difficult to compare quantitatively predictions and observations even though the two should be of the same magnitude, as it is the case here. This comparison is instrumental in defining the relevance of the range of final velocities $\left(1.4\right.$ to $\left.7 \mathrm{~cm} \mathrm{a}^{-1}\right)$.

[66] It should be noted that this range is 3 to 10 times larger that the exhumation rate along the ETSZ $(5-6 \mathrm{~mm}$ $\mathrm{a}^{-1}$, Figure 10). This last range is an average exhumation rate over $10 \mathrm{Ma}$ and is not in contradiction with a velocity increase during a period less than $1 \mathrm{Ma}$.

\section{Concluding Discussion}

[67] The aim of this paper is to test the assumption that the feldspar to white mica reaction controlled by microfracturing could be the destabilizing factor for strain localization at midcrustal depth.

[68] This assumption is inferred from a field study of the East Tenda shear zone, Alpine Corsica. This shear zone has a width of approximately $2 \mathrm{~km}$ and, according to PT data, was formed at a depth of the order of $15 \mathrm{~km}$. The motion along this extensional shear zone is found to be of the order of $5-6 \mathrm{~mm} \mathrm{a}^{-1}$ and the time for its formation and its activation (e.g., exhumation of the HP-LT rocks) is less than $10 \mathrm{Ma}$. The percentage of mica varies from $10 \%$ to $50 \%$, approximately, as one moves from the outer boundary of the shear zone toward the region of intense shearing. This variation is due to the transformation of feldspar into white mica initiated from fractured coarse grains.

[69] A mechanical model is proposed to capture the onset of strain localization and thus to test our assumption on the role of the feldspar-to-mica reaction. The layered structure studied is composed of a rigid upper crust gliding over the lower crust which sustains an overall simple shear mode of deformation. The rheological model considered applies to a mixture of three phases (mica, feldspar and quartz) which are sustaining the same strain rate assuming dislocation creep for each phase. Feldspar having a steady flow stress larger than mica, a decrease in the concentration of feldspar balanced by an increase in mica concentration leads to a reduction in flow stress of the mixture. The feldspar-to-mica reaction takes place if the Mohr-Coulomb criterion for the feldspar partial stress is met. The rate of change of the mica concentration is proportional to the strain rate, the difference between the current and the final mica concentration, and the kinetics factor $\varphi$. This factor times the strain rate $\dot{\gamma}$ defines locally the characteristic time for this reaction $t_{R}=1 / \varphi \dot{\gamma}$.

[70] The extension of the crust is assumed to result in a velocity change from $V_{\text {init }}$ to $V_{\text {final }}$ in the gliding upper crust during a time lapse denoted $t_{L}$, Figure 11a. After $t_{L}$, the velocity is kept constant at $V_{\text {final }}$ during $\Delta t$. It is found by numerical means that after $t_{L}$, the metamorphic reaction is initiated at a depth of the order of $15 \mathrm{~km}$ resulting ultimately in strain localization. The shear zone is defined as the region where the strain rate is increased by at least two orders of magnitude compared to the steady state strain rate. This increase in strain rate and the presence of a constant shear stress over the whole lower crust lead to a decrease of the secant viscosity $\eta=\tau / \dot{\gamma}$ by two orders of magnitude, as seen in Figure 11c, which marks the onset of localization. Strain localization is a two stages process, the first one being 
characterized by an increase of the strain rate in a narrow region and a decrease outside that region. This decrease is due to the necessity of having a constant average strain rate over the lower crust to enforce the constant velocity boundary condition. This decrease leads to the deactivation of the Mohr-Coulomb criterion and defines the upper boundary of the shear zone. The second stage takes place once the final mica content has been reached where the strain rate is maximum. The destabilizing effect there is not active anymore and the strain rate becomes homogeneous over the shear zone.

[71] The increase in the upper crust velocity has to be at least by a factor of five ( $V_{\text {final }}>5.3 V_{\text {init }}$ ) for localization to take place. This increase is required to raise the feldspar partial stress above the critical Mohr-Coulomb threshold, which controls the onset of the metamorphic reaction, Figure 11b. The friction coefficient which enters the Mohr-Coulomb criterion influences the shear zone depth. The selected value of 0.2 approximates the depth-dependence of feldspar fracturing, as shown by Gueydan et al. [2001]. Moreover, this selection leads to a reaction at a depth of $15-17 \mathrm{~km}$ which is consistent with field observations in the ETSZ. The second parameter which controls the depth of the shear zone is the time lapse $t_{L}$. This time has to be short compared to the heat conduction time over the lower crust so that the shear stress can increase from the steady state values. As a consequence, and because of the pressure dependency of the reaction onset, the depth of the shear zone increases with shorter $t_{L}$. A critical value of $140 \mathrm{ka}$ for $t_{L}$ was found for localization to occur.

[72] The position of the upper boundary of the localization zone is determined by the depth where the reaction ceased by the deactivation of the Mohr-Coulomb criterion. The width of the shear zone ranges approximately between one and four $\mathrm{km}$ and is largest for the most rapid metamorphic reaction (largest $t_{R}$ ) and for the largest final mica concentration. Those two factors control the importance of the destabilizing factor and the timing of the strain localization process. The time interval prior to the MohrCoulomb deactivation is necessarily controlled by the importance of the destabilizing factor. This critical time interval is estimated to be of the order of $140 \mathrm{ka}$. The timing of the shear zone formation can thus be summarized as follows. An increase of the upper crust velocity during a short time lapse $\left(t_{L}\right.$ less than $\left.140 \mathrm{ka}\right)$ induces feldspar fracturing and leads to the onset of the feldspar-to-mica reaction. At a constant upper crust velocity, the rapid increase of mica concentration in a narrow region during a time interval less than $140 \mathrm{ka}$ results in the formation of the shear zone. The time required to initiate and to form the shear zone is thus less than half a million year. This short time is consistent with the relatively rapid exhumation (less than $10 \mathrm{Ma}$ ) at midcrustal condition for the ETSZ. Note that the upper crust velocities are 3 to 10 times larger than the estimated exhumation rate along the ETSZ. This exhumation rate is an average value over $10 \mathrm{Ma}$ and is therefore not in contradiction with a velocity increase during a short period of time (less than $500 \mathrm{ka}$ ).

[73] The predicted depth $(15-17 \mathrm{~km})$ and width $(1-4$ $\mathrm{km}$ ) of the shear zones are consistent with the geological observations reported within the ETSZ. These findings validate the assumption that reaction-softening controlled by a pressure-sensitive criterion can explain the onset of localization in the ETSZ.

[74] The proposed simple mechanical model has thus some merits but should be amended in the future to clarify the role of the fluids at the depth of localization. To be more specific, one should recall that a mole of transformed feldspar requires a mole of $\mathrm{H}_{2} \mathrm{O}$. Field evidence [see, e.g., Patriat and Jolivet, 1998] suggest that extensional shear zones at the brittle-ductile transition correspond to highpermeability zones, where fluids percolate, explaining the formation of a large number of quartz-rich veins. The presence of free fluid is thus highly probable and should influence the kinetics of the metamorphic reaction. A realistic model which would describe the evolution in time of the permeability is not available and deserve a complete study on its own. For the time being, it is shown that the kinetics factor $\varphi$ which depends on the amount of available fluids and thus on the unknown permeability, contributes to the reaction time $t_{R}$, which partially controls the timing of strain localization. The kinetics factor $\varphi$ must take a minimum value to trigger strain localization. Furthermore, an increase of the kinetic parameter by one order of magnitude compared to the minimum value leads to a thickening of the shear zone by a factor of three.

[75] The metamorphic reaction considered herein is a particular example of reactions which are taking place in the continental crust and are potentially leading to strain localization. During exhumation of HP-LT metamorphic rocks, the formation of large scale shear zones, either in the ductile lithospheric mantle or in the lower crust, is coeval with retrograde metamorphic reactions (garnet to chlorite reaction [Grambling, 1990] and see, e.g., Newman et al. [1999] for reactions in peridotite). These reactions share the common feature with the feldspar to white mica reaction that a stronger phase is replaced by a weaker phase. The simple model proposed here could thus be extended to account for these various reactions with the same general result: the transformation introduces a destabilizing effect which is ultimately responsible for the strain to localize.

\section{Appendix A: Dimensional Analysis}

[76] Dimensionless length, temperature, equivalent shear stress, time and strain rate are defined by

$$
y=\frac{\bar{y}}{\bar{d}}, T=\frac{\bar{T}}{\bar{T}_{o}}, \tau=\frac{\bar{\tau}}{\bar{\tau}_{c}}, t=\frac{\bar{t}}{\bar{t}_{c}}, \dot{\gamma}=\frac{\dot{\bar{\gamma}}}{\dot{\bar{\gamma}}_{c}},
$$

in which, $\bar{d}, \bar{T}_{o}$ and $\bar{\tau}_{c}$ are the thickness of the lower crust $(20 \mathrm{~km})$, the characteristic temperature of the lower crust (set to $800^{\circ} \mathrm{K}$ and corresponding to the average temperature of the lower crust) and the characteristic shear stress, respectively. The characteristic time $\bar{t}_{c}$ is based on the heat conduction within the lower crust $(14 \mathrm{Ma})$ and provides the characteristic strain rate, $\dot{\bar{\gamma}}_{c}=\frac{1}{t_{c}}$. The values of these characteristic parameters are summarized in Table 2. The characteristic shear stress depends on the experimental flow laws extrapolated from laboratory experiments, which are given in the following form:

$$
\dot{\bar{\gamma}}=\bar{A} \exp \left[-\frac{\bar{Q}}{\bar{R} \bar{T}}\right] \bar{\tau}^{n}
$$


where $\bar{Q}, \bar{A}, n$ and $\bar{R}$ are the activation energy for dislocation creep, the preexponential constant, the stress exponent and the universal gas constant, respectively. The values of these constants are from Shelton and Tullis [1981], Koch et al. [1989], and Kronenberg et al. [1990] for feldspar, quartz and mica (biotite), respectively, and are presented in Table 1). Identifying equations (A2) and (2), the dimensionless parameters and characteristic values of the flow law read:

$$
\beta_{\alpha}=\frac{\bar{Q}}{\bar{R}_{\bar{T}}}, \bar{\tau}_{R \alpha}=\left[\frac{\dot{\bar{\gamma}}_{R \alpha} \exp \left(\beta_{\alpha}\right)}{\bar{A}}\right]^{\frac{1}{n_{\alpha}}},
$$

in which the strain rate $\dot{\bar{\gamma}}_{R \alpha}$ is set to $\dot{\bar{\gamma}}_{c}$ [Gueydan et al., 2001]. Having defined the characteristic shear stress for each mineral, $\bar{\tau}_{R \alpha}$, the characteristic shear stress is selected as the smallest value of the three:

$$
\bar{\tau}_{c}=\min _{\alpha=f, q, m}\left(\bar{\tau}_{R \alpha}\right)
$$

corresponding to $2.4 \mathrm{MPa}$ (Table 2).

\section{Notation}

$\bar{a}, a$ Physical variable or parameter $\bar{a}$ and its dimensionless expression $a$

$\bar{a}_{c} \quad$ Characteristic value of variable $\bar{a}$, used for dimensional analysis: $a=\bar{a} / \bar{a}_{c}$

REV Representative Elementary Volume

$\bar{t}_{c} \quad$ Characteristic heat conduction time within the lower crust

$\tau$ Overall shear stress in the lower crust

$p$ Lithostatic pressure in the lower crust

$V$ Upper crust gliding velocity

$y$ Normalized y coordinate axis has its origin at the Moho and the coordinate $y=1$ is at the upper crust contact

$t_{L} \quad$ Time lapse during which $V$ is changed

$\Delta t$ Time interval during which $V$ is kept constant

$\dot{\gamma}$ Strain rate in the lower crust

$\eta$ Secant viscosity in the lower crust, defined by $\eta=$ $\tau / \dot{\gamma}$

$T$ Temperature

$\alpha$ Subscript which stands for either $f, q$ or $m$, corresponding to feldspar, quartz or mica phase, respectively

$\tau_{\alpha} \quad$ Partial shear stress for phase $\alpha$

$C_{\alpha} \quad$ Volumetric proportion of phase $\alpha$

$\dot{C}_{m} \quad$ Rate of change of mica concentration

$C_{m}^{\star} \quad$ Final mica concentration, measured in the mylonite (ETSZ)

$\varphi$ Kinetics factor for the metamorphic reaction

$t_{R}$ Reaction time at a constant strain rate, defined by $1 / \varphi \dot{\gamma}$

$\mu \quad$ Friction coefficient

$\delta$ Mohr-Coulomb parameter (0 or 1$)$ to mark the fracturing of feldspar

[77] Acknowledgments. The constructive review of C. A. J. Wibberley considerably helped us to improve the manuscript. J. Tullis provided, independently of the review process, useful comments on the first version of the manuscript. The authors would like to thank both of them.

\section{References}

Agard, P., O. Vidal, and B. Goffé, Interlayer and Si content of phengite in HP-LT carpholite-bearing metapelites, J. Metamorph. Geol., 19, $477-$ 493, 2001.

Brace, W. F., and D. L. Kohlstedt, Limits on lithospheric stress imposed by laboratory experiments, J. Geophys. Res., 85, 6248-6252, 1980.

Brown, P. E., and W. M. Lamb, P-V - T properties of fluids in the system $\mathrm{H}_{2} \mathrm{O}+-\mathrm{CO}_{2}+-\mathrm{NaCl}$ : New graphical presentations and implications for fluid inclusion studies, Geochim. Cosmochim. Acta, 53, 109-1221, 1989.

Brunet, C., P. Monié, L. Jolivet, and J. P. Cadet, Migration of compression and extension in the Tyrrhenian Sea, insights from 40Ar/39Ar ages on micas along a transect from Corsica to Tuscany, Tectonophysics, 321, $127-155,2000$.

Carmichael, I. S. E., F. J. Turner, and J. Verhoogen, Igneous Petrology, 739 pp., McGraw-Hill, New York, 1974.

Caron, J. M., J. R. Kienast, and C. Triboulet, High pressure-low temperature metamorphism and polyphase Alpine deformation at Sant' Andrea di Cotone (Eastern Corsica, France), Tectonophysics, 78, 419-451, 1981.

Daniel, J. M., L. Jolivet, B. Goffé, and C. Poinssot, Crustal-scale strain partitionning: Footwall deformation below the Alpine Corsica OligoMiocene detachement, J. Struct. Geol., 18, 41-59, 1996.

Davis, G. H., Shear-zone model for the origin of metamorphic core complexes, Geology, 11, 342-347, 1983.

Dixon, J., and G. Williams, Reaction softening in mylonites from the Arnaboll thrust, Sutherland, Scott. J. Geol., 19(2), 157-168, 1983.

Evans, B. W., Phase relations in epidote-blueschists, Lithos, 25, 3-23, 1990.

Ferrandini, M., J. Ferrandini, M.-D. Löye-Pilot, J. Butterlin, J. Cravatte, and M. C. Janin, Le Miocène du bassin de Saint Florent (Corse): Modalités de la transgression du Burdigalien supérieur et mise en évidence du Serravalien, Geobios, 31(1), 125-137, 1996.

Ferry, J. M., A historical review of metamorphic fluid flow, J. Geophys. Res., 99, 15,487-15,498, 1994.

Fitz Gerald, J. D., and H. Stünitz, Deformation of granitoids at low metamorphic grade, 1, Reactions and grain size reduction, Tectonophysics, 221, 269-297, 1993.

Fleitout, L., and C. Froidevaux, Thermal and mechanical evolution of shear zones, J. Struct. Geol., 2, 159-164, 1980.

Fournier, M., L. Jolivet, B. Goffé, and R. Dubois, The Alpine Corsica metamorphic core complex, Tectonics, 10, 1173-1186, 1991.

Gapais, D., Shear structures within deformed granites: Mechanical and thermal indicators, Geology, 17, 1144-1147, 1989.

Grambling, J. A., Internally-consistent geothermometry and $\mathrm{H}_{2} \mathrm{O}$ barometry in metamorphic rocks; the example garnet-chlorite-quartz, Contrib. Mineral. Petrol., 105, 617-628, 1990.

Gueydan, F., The brittle-ductile transition of an extending continental crust. Field study and mechanical modelling, Doctoral thesis, Univ. Pierre et Marie Curie, Paris, 2001.

Gueydan, F., Y. M. Leroy, and L. Jolivet, Grain size sensitive flow and shear stress enhancement at the brittle-ductile transition of the continental crust, Int. J. Earth Sci., 90(1), 181-196, 2001.

Handy, M. R., The solid-state flow of polymineralic rocks, J. Geophys. Res., 95, 8647-8661, 1990.

Handy, M. R., S. B. Wissing, and L. E. Streit, Frictional-viscous flow in mylonite with varied bimineralic composition and its effect on lithospheric strength, Tectonophysics, 303, 175-191, 1999.

Hemley, J. J., and W. R. Jones, Chemical aspects of hydrothermal alteration with emphasis on hydrogen metasomatism, Econ. Geol., 59, 538-569, 1964.

Hirth, G., and J. Tullis, Dislocation creep regimes in quartz aggregates, J. Struct. Geol., 14, 145-159, 1992.

Jakni, B., G. Poupeau, M. Sosson, P. Rossi, J. Ferrandini, and P. Guennoc, Cenozoic denudations in Corsica: An analysis from apatite fission-track thermochronology, C. R. Acad. Sci., Ser. IIa Sci. Terre Planetes, 331, $775-782,2000$.

Jolivet, L., R. Dubois, M. Fournier, B. Goffé, A. Michard, and C. Jourdan, Ductile extension in Alpine Corsica, Geology, 18, 1007-1010, 1990.

Jolivet, L., et al., Midcrustal shear zones in postorogenic extension: Example from the northern Tyrrhenian Sea, J. Geophys. Res., 103, 12,12312,160, 1998.

Kirby, S. H., Rock mechanics observations pertinent to the rheology of the continental lithosphere and the localization of strain along shear zones, Tectonophysics, 119, 1-27, 1985.

Kirby, S. H., and A. K. Kronenberg, Rheology of the lithosphere: Selected topics, Rev. Geophys., 25(6), 1219-1244, 1987. 
Knipe, R. J., and R. P. Wintsch, Heterogeneous deformation, foliation development and metamoprhic processes in a polyphase mylonite, in Advances in Physical Geochemistry, edited by A. B. Thompson and D. C. Rubie, pp. 180-210, Springer-Verlag, New York, 1985.

Koch, P. S., J. C. Christie, A. Ord, and J. R. P. George, Effect of water on the rheology of experimentally deformed quartzite, J. Geophys. Res., 94, 13,975-13,996, 1989.

Kronenberg, A. K., S. H. Kirby, and J. Pinkston, Basal slip and mechanical anisotropy of biotite, J. Geophys. Res., 95, 19,257-19,278, 1990.

Lister, G. S., and G. A. Davis, The origin of metamorphic core complexes and detachment faults formed during Tertiary continental extension in the northern Colorado River region, U.S.A., J. Struct. Geol., 11, 65-94, 1989.

Mares, V. M., and A. K. Kronenberg, Experimental deformation of muscovite, J. Struct. Geol., 15, 1061-1075, 1993.

Mattauer, M., M. Faure, and J. Malavieille, Transverse lineation and large scale structures related to Alpine obduction in Corsica, J. Struct. Geol., 3, 401-409, 1981.

Miller, E. L., P. B. Gans, and J. Garing, The snake range decollement: An exhumed mid-tertiary ductile-brittle transition, Tectonics, 2, 239-263, 1983.

Mitra, G., Ductile deformation zones and mylonites: The mechanical process involved in the deformation of crystalline basement rocks, Am. J. Sci., 278, 1057-1084, 1978.

Newman, J., W. N. Lamb, M. R. Drury, and R. L. M. Vissers, Deformation processes in a peridotite shear zone: Reaction-softening by an $\mathrm{H}_{2} \mathrm{O}$-deficient, continuous net transfer reaction, Tectonophysics, 303, 193-222, 1999.

Oberhänsli, R., B. Goffé, and R. Bousquet, Record of a HP-LT metamorphic evolution in the Valais zone, in Studies on Metamorphic Rocks and Minerals of the Western Alps, edited by B. Lombardo, pp. 221-239, Mus. Reg. di Sci. Nat., Torino, Italy, 1995.

Patriat, M., and L. Jolivet, Post-orogenic extension and shallow-dipping shear zones, study of a brecciated decollement horizon in Tinos (Cyclades, Greece), C. R. Acad. Sci., Ser. I, 326, 355-362, 1998.

Poirier, J. P., Shear localization and shear instability in materials in the ductile field, J. Struct. Geol., 2, 135-142, 1980.

Pryer, L. L., Microstructures in feldspars from a major crustal thrust zone: The Grenville front, Ontario, Canada, J. Struct. Geol., 15, 21-36, 1993.

Rigo, A., H. Lyon-Caen, R. Armijo, A. Deschamps, D. Hatzfeld, K. Makropoulos, P. Papadimitriou, and I. Kassaras, A microseismicity study in the western part of the Gulf of Corinth (Greece): Implications for largescale normal faulting mechanisms, Geophys. J. Int., 126, 663-688, 1996.
Shea, W. T., and A. K. Kronenberg, Strength anisotropy of foliated rocks with varied mica contents, J. Struct. Geol., 15, 1097-1121, 1993.

Shelton, G., and J. Tullis, Experimental flow laws for crustal rocks, Eos Trans. $A G U, 62(17), 396,1981$.

Simpson, C., Deformation of granitic rocks across the brittle-ductile transition, J. Struct. Geol., 7, 503-511, 1985.

Tullis, J., and R. A. Yund, Dynamic recrystallization of feldspar: A mechanism for ductile shear zone formation, Geology, 13, 238-241, 1985.

Tullis, J., and R. A. Yund, Transition from cataclastic flow to dislocation creep of feldspar: Mechanisms and microstructures, Geology, 15, 606609, 1987

Tullis, T. E., F. G. Horowitz, and J. Tullis, Flow Laws of Polyphase aggregates form end-member flow laws, J. Geophys. Res., 96, 8081-8096, 1991.

Walther, J. V., and P. M. Orville, Volatile production and transport in regional metamorphism, Contrib. Mineral. Petrol., 79, 252-257, 1982.

Waters, C. N., The metamorphic evolution of the Schistes lustrés ophiolite, Cap Corse, Corsica, in Evolution of Metamorphic Belts, edited by J. S. Daly, R. A. Cliff, and B. W. D. Yardley, pp. 557-562, Blackwell, Malden, Mass., 1989.

Wells, M. L., Rheological control on the initial geometry of the Raft River detachment fault and shear zone, western United States, Tectonics, 20, 435-457, 2001.

Wernicke, B., Cenozoic extensional tectonics of the cordillera, U.S., in The Cordilleran Orogen: Conterminous U.S., edited by B. C. Burchfiel, P. W. Lipman, and M. L. Zoback, pp. 553-581, Geol. Soc. of Am., Boulder, Colo., 1992

White, S. H., and R. J. Knipe, Transformation- and reaction-enhanced ductility in rocks, J. Geol. Soc. London, 135, 513-516, 1978.

Wibberley, C. A. J., Are feldspar-to-mica reactions necessarily reactionsoftening process in fault zones, J. Struct. Geol., 21, 1219-1227, 1999.

P. Agard and L. Jolivet, Laboratoire de Tectonique, Université Pierre et Marie Curie, UMR CNRS 7072, Case 129, 4 place Jussieu, 75252 Paris, Cedex 05, France.

F. Gueydan (corresponding author), Géosciences Rennes, UMR CNRS 6118, Université de Rennes 1, Bat 15, Campus Beaulieu 35043 Rennes Cedex, France. (frederic.gueydan@univ-rennes1.fr)

Y. M. Leroy, Laboratoire de Mécanique des Solides, Ecole polytechnique, UMR CNRS 7649, 91128 Palaiseau Cedex, France. (leroyy@lms. polytechnique.fr) 


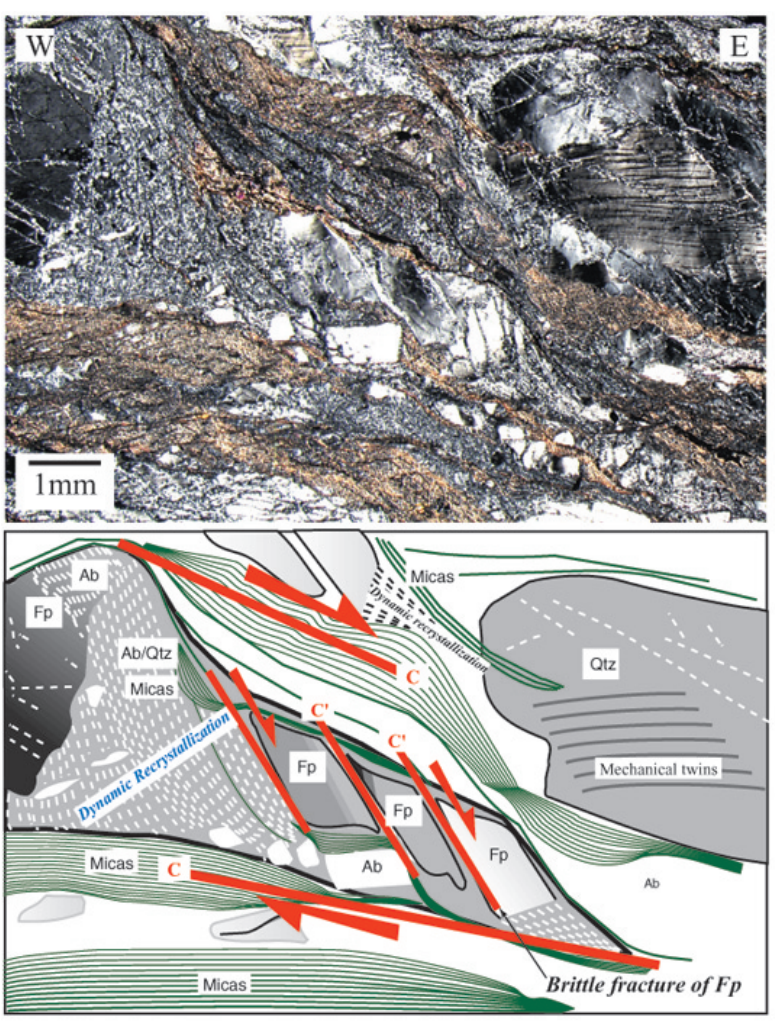

a
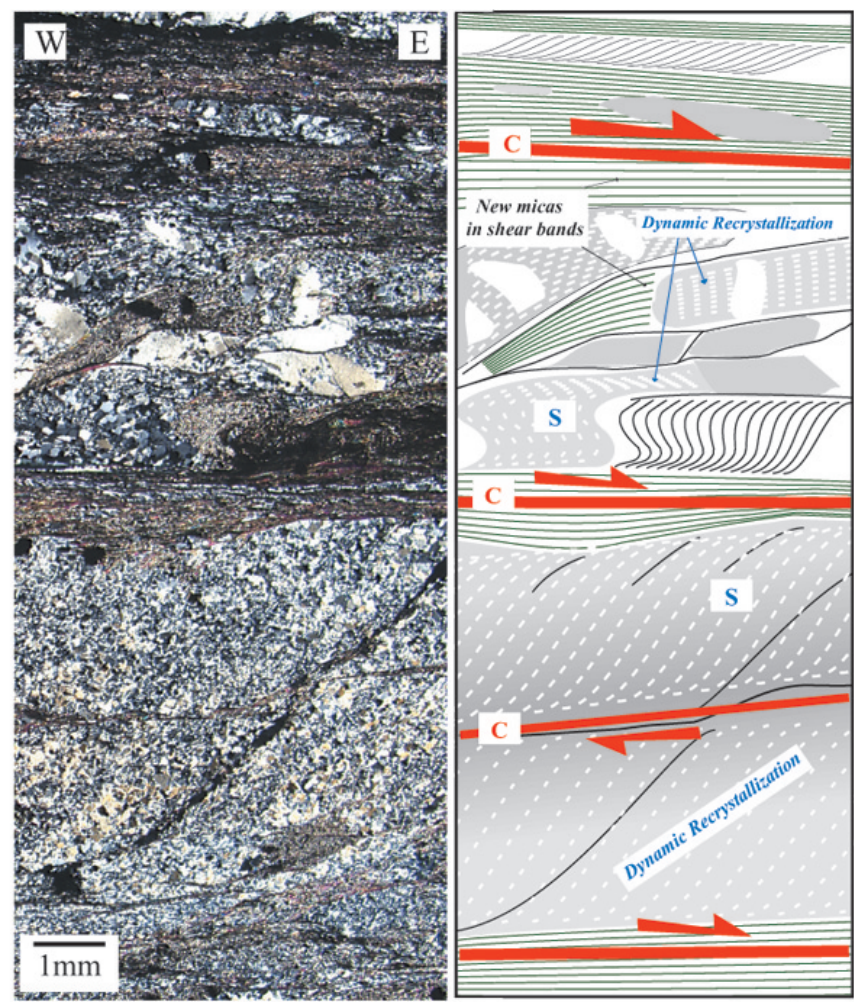

b

Figure 3. Thin sections, oriented $\mathrm{W}-\mathrm{E}$, and their interpretation. In a) from site 1 (Figure 2), a coarse feldspar grain is fractured and rimmed by a mantle of white mica. Quartz grain presents thin intracrystalline dynamic recrystallization bands. In b) from site 2, C-planes are essentially made of an aggregate of fine-grained white mica. The mean recrystallized grain size reaches a value of approximately $100 \mu \mathrm{m}$. 